\title{
Maintenance Optimization for Power Distribution Systems Subjected to Hurricane Hazard, Timber Decay and Climate Change
}

\begin{abstract}
Abdullahi M. Salmana, ${ }^{a}$, Yue Li $^{\mathrm{a}}$, Emilio Bastidas-Arteaga ${ }^{\mathrm{b}}$
Abstract: Electric power systems are vulnerable to extensive damage due to hurricanes with most of the damage concentrated on overhead distribution systems. There is evidence that climate change will affect future hurricane patterns. Additionally, wood poles, which are most commonly used in distribution systems, are susceptible to decay. The scarcity of resources and increasing demand for higher reliability warrant the use of optimization techniques for wood pole maintenance planning. This paper presents a framework for optimal maintenance of wood poles subjected to non-stationary hurricane hazard and decay. Maintenance cost, service life, and system performance are considered separately and simultaneously in the optimization. Periodic chemical treatment and repair of decayed poles using fiber-reinforced polymer are considered. The distribution system of a virtual city assumed to be in Florida is used to demonstrate the framework. The results of the single-objective optimization indicate that the objective that maximizes service life resulted in higher optimal maintenance time. However, delaying maintenance will lead to a larger probability of pole failure, higher corrective maintenance cost, and lower system performance. The result of the multiobjective optimization is closer to the result of the cost-based optimization because the cost function is more sensitive to the variation of maintenance time.
\end{abstract}

Keywords: Wood pole, power systems, reliability, hurricanes, climate change, decay, maintenance optimization.

\section{Introduction}

Asset management is one of the crucial aspects of concern to decision makers such as power distribution companies and involves several actions such as component acquisition, maintenance, replacement, and disposition. One of the most important aspects of asset management is preventive or corrective maintenance. The purpose of such maintenance measures is to extend the service life of components and/or reduce their probability of failure. Utility companies are constantly exploring ways to optimize the use of available resources for maintenance while ensuring an acceptable level of reliability.

Overhead power distribution systems consist of conductors and other electrical equipment supported by poles. The large number of such distribution poles make them critical to overall asset management in distribution systems not only because of their impact on reliability but also in terms of cost. For example, there are an estimated 5 million wood poles in Australia, with a net worth of over $\$ 10$ billion [1,2]. In the United States (U.S.), it is estimated that there are between 160 million and 180 million wood poles supporting distribution and transmission networks [3].

a Department of Civil Engineering, Case Western Reserve University, 10900 Euclid Avenue, Cleveland, OH 44106, USA.

${ }^{\mathrm{b}}$ UBL, Université de Nantes, GeM, Institute for Research in Civil and Mechanical Engineering/Sea and Littoral Research Institute, CNRS UMR 6183/FR 3473, Nantes, France

* Corresponding author. Email: amsalman@mtu.edu 
Wood poles are mostly used due to advantages such as low initial cost and natural insulation properties [4]. Wood poles are, however, susceptible to decay over time which leads to decrease in strength [5]. As such, utility companies carry out periodic inspections and necessary maintenance of wood poles over time. Given the scale of pole networks and their susceptibility to decay, it is reasonable to assume that a systematic risk-based or reliability-based maintenance policy would lead to considerable cost savings and failure risk mitigation.

Power distribution systems, especially the distribution poles and lines, are susceptible to extensive damage due to hurricanes. For example, in 1992, Hurricane Andrew caused the failure of about 10\% of distribution poles which resulted in a power outage to $44 \%$ of customers of Florida Power \& Light [6, 7]. In 2004, four major hurricanes struck Florida causing a combined economic loss of over $\$ 20$ billion and damaging every segment of Florida's electricity infrastructure which resulted in a power outage to over 9.6 million customers combined [8]. The impact of hurricanes on distribution systems is compounded when the potential impact of climate change is considered. The Fifth Assessment Report of the Intergovernmental Panel on Climate Change (IPCC) noted a variation in weather patterns and projected an increase in the intensity of storms [9, 10]. Gutowski et al. [11] projected that a $1.6^{\circ} \mathrm{C}$ rise in sea surface temperature could increase tropical wind speeds by as much as $13 \%$, with $10 \%$ to $31 \%$ more precipitation. This implies that both the strength of poles and hazard intensity are time-dependent and a comprehensive long-term maintenance policy should take these new climate conditions into account.

In the face of limited resources available for preventive maintenance, an optimization approach is necessary. While maintenance optimization for electrical components of distribution systems considering common cause failures has been studied (e.g. Hilber et al. [12], Lehtonen [13], Abbasi et al. [14], Sittithumwat et al. [15], Arab et al. [16]), research on maintenance optimization for distribution poles subjected to hurricane hazard considering the potential impact of climate change is scarce. Ryan et al. [2] presented a framework for the reliability assessment of treated and untreated distribution poles subjected to wind load incorporating deterioration and network maintenance using an event-based Monte Carlo simulation. While the framework advances the state-of-the-art by incorporating network maintenance, it did not attempt to optimize maintenance strategies nor consider system performance. Winkler et al. [17] present a methodology for combining hurricane damage predictions and topological properties to investigate the impact of hurricanes on system reliability. Substations, transmission lines, and distribution lines were considered in the study. System reliability was found to correlate with topological features such as meshedness, centrality, and clustering.

Other research on distribution poles subjected to hurricane hazard includes Bjarnadottir et al. [18], Gustavsen and Rolfseng [19], and Francis et al. [20]. These papers, however, did not consider preventive maintenance of the poles, system performance, and optimization. Datla and Pandey [21] developed a probabilistic model for estimating the life expectancy of wood poles as well as determining the optimal replacement age based on cost. Pierson and Blanc [22] studied the impact of various factors such as specie, pole size, nature of attachments, location, and material imperfection on the optimal replacement time of wood poles based on cost. Preventive maintenance and system performance was, however, not considered. 
This paper presents a framework for optimal maintenance of distribution poles subjected to non-stationary hurricane wind hazard. The framework considers system performance using a topological-based probabilistic performance measure, cost constraints, climate change impact, and decay. In addition, both corrective and preventive maintenance of the system are considered. Three objectives are considered separately and simultaneously in the optimization: cost, service life of poles, and system performance. The optimization based on cost is constraint to the total lifetime length while the optimization based on service life and system performance are constraint to account for pole residual strength requirement. Fig. 1 shows a general flow chart of the proposed framework. The proposed framework is demonstrated using a notional power distribution system assumed to be located on the east coast of Florida in the U.S. Two preventive maintenance strategies are considered: a time-based chemical treatment and a condition-based repair using fiber reinforced polymer (FRP). The developed framework can be used for a more efficient and optimal use of resources to improve reliability and prolong the service life of distribution support structures considering uncertainty in both strength and applied load due to hurricane hazard.

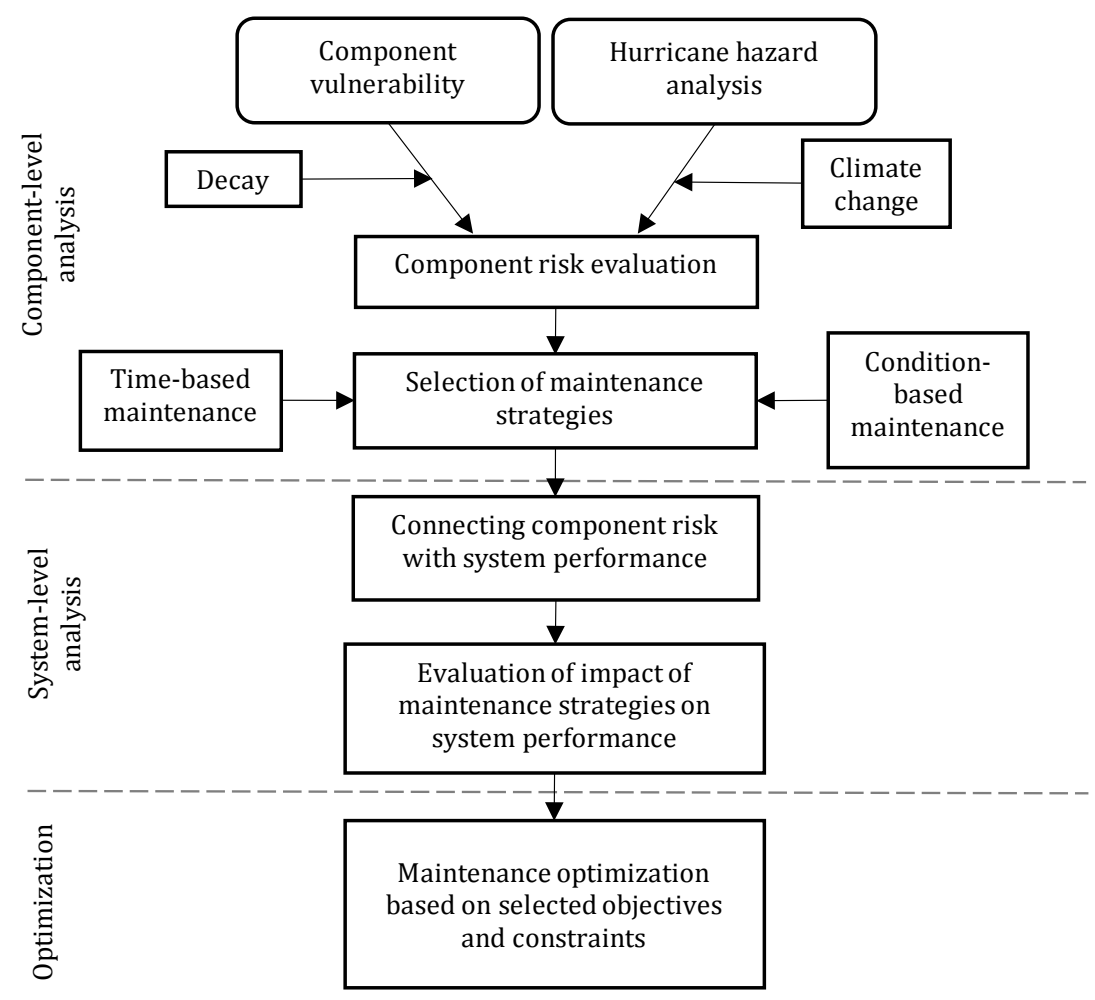

Figure 1: General flowchart of proposed framework

The paper is organized as follows: Section 2 presents the methodology used for component and network risk assessment. Section 3 describes the considered maintenance strategies as well as the framework for maintenance optimization. Section 4 illustrates the proposed methodology with a case study focusing on the maintenance optimization of a power distribution system of a 5,000-resident virtual city. 


\section{Component and Network Risk Assessment}

\subsection{Component Risk Assessment}

As mentioned earlier, the vulnerable components considered in this research are the wood distribution poles supporting overhead lines. Component risk here is defined as the annual probability of failure of poles which is given by Equation (1):

$$
P_{f}=\int_{0}^{\infty} F_{R}(v, t) f_{v}(v, t) d v
$$

where $F_{R}(v, t)$ is the time-dependent cumulative distribution function (CDF) of component structural fragility, and $f_{v}$ $(v, t)$ is the time-dependent probability density function (PDF) of the annual maximum hurricane wind speed. The next two sections describe the evaluation of the time-dependent component fragility and hurricane wind load.

\subsubsection{Time-dependent Component Vulnerability}

The vulnerability of the poles is quantified using fragility analysis performed using Monte Carlo Simulation. The limit state function for the fragility analysis is given by Equation (2):

$$
G(t)=R(t)-S(t)
$$

where $R(t)$ is the time-dependent strength of the poles; $S(t)$ is the load demand (i.e. bending stress) at the ground line. Note that only flexural failure is considered in this research as it is the most common failure model for wood poles [17]. If data is available, other failure modes such as foundation failure and failure due to flying debris and falling trees can be easily incorporated into the framework. The steps of the fragility analysis are summarized in Fig. 2.

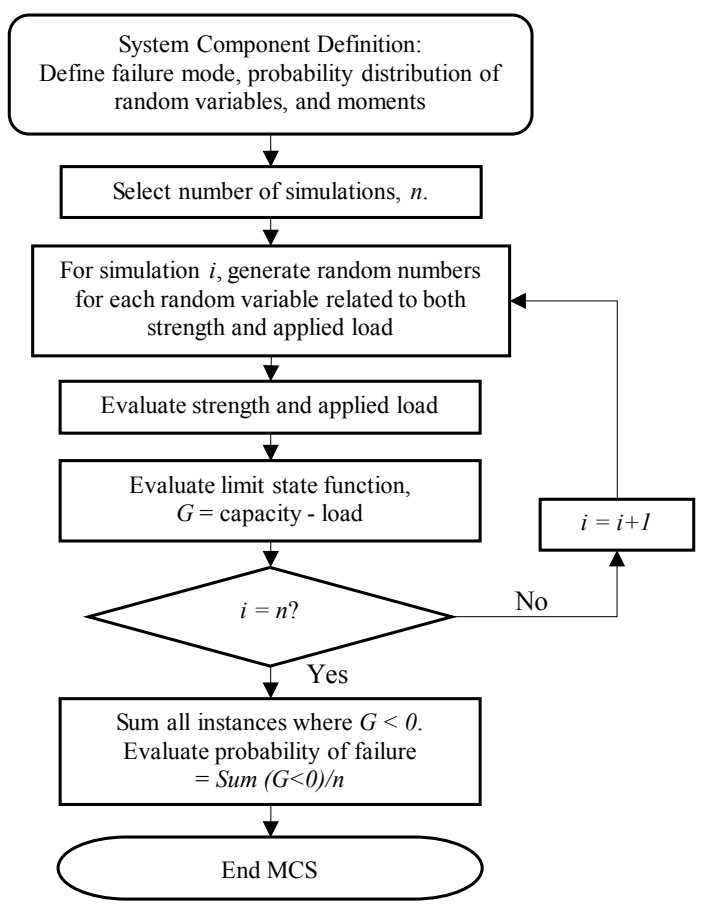

Figure 2 Fragility analysis flowchart 
Lognormal distribution has been shown to be appropriate to model fragility of wood distribution poles [18, 23]. The time-dependent cumulative distribution function $(\mathrm{CDF})$ of component structural fragility, $F_{R}(v, t)$, in Equation (1) is therefore modeled by the lognormal distribution given by Equation (3):

$$
F_{R}(v, t)=\Phi\left[\frac{\ln (v / m)}{\zeta}\right]
$$

where $m$ is the median of the fragility function; $\zeta$ is the logarithmic standard deviation of intensity measure; and $v$ is wind speed.

As a natural material, wood is susceptible to decay over time due mainly to biodeterioration of fungi or other living organisms. The decay of wood distribution poles usually occurs at or near the groundline [24]. The rate of decay is site- and material-specific. Factors that affect the rate of decay include specie of wood, soil properties, climatic conditions (temperature, rainfall, humidity), initial preservative treatment, and the nature of the fungal attack. As such, decay models are location-specific and utility companies need to develop their own models for a more accurate assessment. Due to the numerous factors and considerable uncertainty in wood pole decay, few wood pole decay models are available in the literature.

Wang et al. [25] developed a fungi-induced decay model for Australian wood products in contact with the ground. The model was developed based on three field test of samples from various wood species. The first field test involved 77 untreated species buried for 35 years at five different sites. The second test involved untreated radiata pine sapwood samples buried for 2.5 years at 38 locations while the third test involved 3 treated species at three test sites for about 30 years. The developed model takes into account the material properties, climate condition, and preservative treatment. The model assumes that decay follows an idealized bilinear relation over time and is characterized by two parameters: time lag before decay starts and decay rate. The two parameters are correlated and are given by Equation (4) and (5) [25]:

$$
\begin{gathered}
r=k_{\text {wood }} k_{\text {climate }} \\
t_{\text {lag }}=5.5 r^{-0.95}
\end{gathered}
$$

where $r$ is the decay rate $\left(\mathrm{mm} /\right.$ year) for untreated wood; $k_{\text {wood }}$ is the wood parameter; $k_{\text {climate }}$ is the climate parameter; and $t_{\text {lag }}$ is the decay time lag. $k_{\text {wood }}$ depends on wood specie and durability class and values are given in Wang et al. [25] for heartwood, sapwood, and core wood. As such, the decay model is a multi-layer deterioration model that accounts for the variation in properties of different layers of wood. Note that for untreated wood poles, the sapwood is usually removed due to its low durability [2]. $k_{\text {climate }}$ accounts for rainfall and temperature for different locations in Australia. Based on Equations (4) and (5), the depth of decay at time $t$ is given by Equation (6). For treated wood, an adjustment factor is given in Wang et al. [25] to account for the effect of chemical treatment.

$$
d_{t}=r\left(t-t_{\text {lag }}\right)
$$


Another decay model was developed by Li et al. [5] and modified by Shafieezadeh et al. [26] for wood poles in the U.S. The model was developed based on data from 13,940 in-service poles with age ranging from 1 to 79 years. The strength of a pole as a function of time is modelled by Equation (7) [26]:

$$
R_{w}(t)=R_{o}\left[1-\min \left(\max \left(a_{1} t-a_{2}, 0\right), 1\right) \times \min \left(\max \left(b_{1} t^{b_{2}}, 0\right), 1\right)\right]
$$

where $R_{w}(t)$ is the strength at time $t$; $R_{o}$ is the initial strength; $a_{1}, a_{2}, b_{1}$, and $b_{2}$ are constants. $R_{o}$ is determined from ANSI-O5.1 [27] for wood poles in the U.S. The values of $a_{1}, a_{2}, b_{1}$, and $b_{2}$ were found from regression analysis as $0.014418,0.10683,1.3 \times 10^{-4}$, and 1.846 respectively by Li et al. [5] and Shafieezadeh et al. [26].

Note that in Equation (7), the $b_{1} t^{b_{2}}$ term represent the percentage of decayed poles as a function of time which is also the conditional probability that a pole at age $t$ is decayed. This is because not all the poles were decayed in the data used to develop the model. As such, Equation (7) directly quantifies the uncertainty in decay occurrence through a stochastic model. The decay model, however, did not consider uncertainty due to both material properties and site conditions which make its application limited.

Fig. 3 shows a comparison between the two decay models discussed above. For the Wang et al. [25] model, untreated southern pine is selected as it is the most dominant specie used in the U.S. for distribution systems [28]. The durability class is assumed to be class 2 based on the average service life of wood poles in the U.S. [18, 29]. In terms of climate, climate class B in [25] is chosen as it has a similar climate with Florida in the U.S. which is the chosen location for the demonstration of the proposed framework $[18,30]$. For the sake of comparison, it is assumed that the wood pole is homogenous so that decay rate is constant throughout the cross section for the Wang et al. [25] model. It should also be noted that the conditional probability of decay term in Equation (7) is ignored to allow comparison.

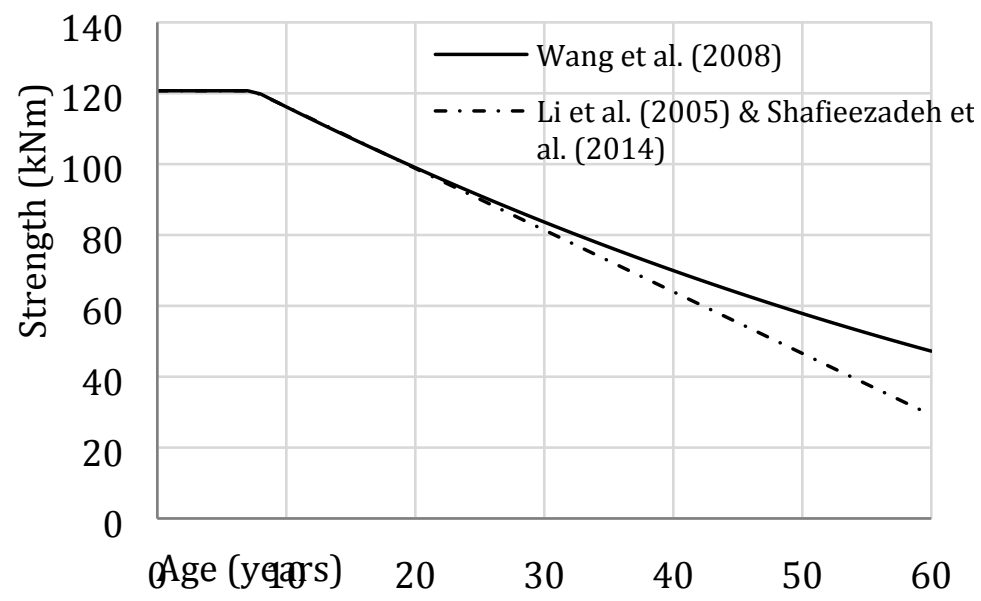

Figure 3: Comparison of wood decay models using ANSI-O5.1 [27] size class 4 southern pine pole

It can be seen from Fig. 3 that the two decay models are very similar especially in the early ages of decay. As pole ages, the models begin to diverge with the Wang et al. [25] model showing slower decay rate. For the purpose of demonstrating the proposed framework, the decay model by Wang et al. [25] is adopted as it explicitly considers 
material properties and climate factors. Therefore, $R(t)$ in Equation (2) is evaluated considering a reduction in diameter due to decay given by Equation (6). Note that the Wang et al. [25] decay model can be calibrated for a specific region if experimental and/or inspection data is available as demonstrated in [31] and [32].

Climate change might influence the decay rate of wood utility poles. Climate patterns such fluctuation in global temperatures, sea surface temperature, rainfall, and humidity can affect climatic and soil factors that govern the decay rate of wood poles. There is, however, no research that attempts to quantify the extent or nature of climate change effect on decay rate. Here, it is assumed that climate change will cause a $\pm 20 \%$ change in wood decay rate to cover a range of potential impact.

The wind load, $S(t)$, in Equation (2) is evaluated using the method recommended by ASCE-111 [33] for both distribution and transmission support structures. Based on this method, the wind force acting on a pole and conductor wires is given by Equation (8) [33, 34]:

$$
F=Q K_{z} K_{z t}(V)^{2} G C_{f} A
$$

where $F$ is force $(\mathrm{N}), Q$ is air density factor, $K_{z}$ is exposure coefficient, $V$ is time-dependent basic 3 -sec gust wind speed, $G$ is gust response factor, $C_{f}$ is force or drag coefficient, $K_{z t}$ is topographic factor, and $A$ is the area projected on a plane normal to the wind direction $\left(\mathrm{m}^{2}\right)$. To account for P- $\Delta$ effect, ASCE-111 [33] recommends using the method developed by Gere and Carter [35] which is adopted in this research.

To perform the fragility analysis, the probability distribution of the strength of the poles is taken as a lognormal distribution [27]. The coefficient of variation (COV) of the initial pole strength is taken as 0.2 [27]. The COV increases after the onset of decay and is approximately given by Equation (9) [36]:

$$
V_{R, t}^{2}=V_{R, 0}^{2}+V_{d e c, t}^{2}
$$

where $V_{R, t}$ is the COV at time $t ; V_{R, 0}$ is the COV of the initial strength; and $V_{\text {dec,t }}$ represents the uncertainty in the decay depth. $V_{d e c, t}$, given by Equation (10), accounts for the uncertainty in the decay parameters, testing variation, and model uncertainty [36]:

$$
V_{d e c, t}=\frac{6 V_{d} \bar{d}_{t}}{D-\bar{d}_{t}}
$$

where $D$ is the initial diameter; $\bar{d}_{t}$ is an estimate of the mean decay depth at time $\mathrm{t}$; and $V_{d}$ is the COV of the uncertainty of decay due to wood parameters. Values of $V_{d}$ for in-ground poles are $0.85,0.9,1.1$, and 1.2 for wood of durability classes $1,2,3$, and 4, respectively [36].

$G$ and $C_{f}$ in Equation (8) are taken as normally distributed with COV of 0.11 and 0.12, respectively [37]; $K_{z}$ is taken as normally distributed with COV of 0.06 [33]; the wind area of the poles and wires is taken as normally distributed with COV of 0.06 [28]; and the pole height above ground is assumed to be normally distributed with a COV of 0.03 . 


\subsubsection{Time-dependent Hurricane Hazard Model}

Time-dependent hurricane hazard to account for the non-stationary wind speed is modeled through a simulation model that allows potential variation in both intensity and frequency of hurricanes to be considered. The flowchart of the simulation model is shown in Fig. 4 and it is based on the model developed by Xu and Brown [38] and described in Salman and Li [39]. The simulation model involves using site-specific statistics of key hurricane parameters and Monte Carlo simulation for assessing hurricane hazard level. Site-specific statistics of parameters can be derived from historical records. Within the simulation, parameters related to intensity and frequency of hurricanes can be modified to account for the potential impact of climate change.

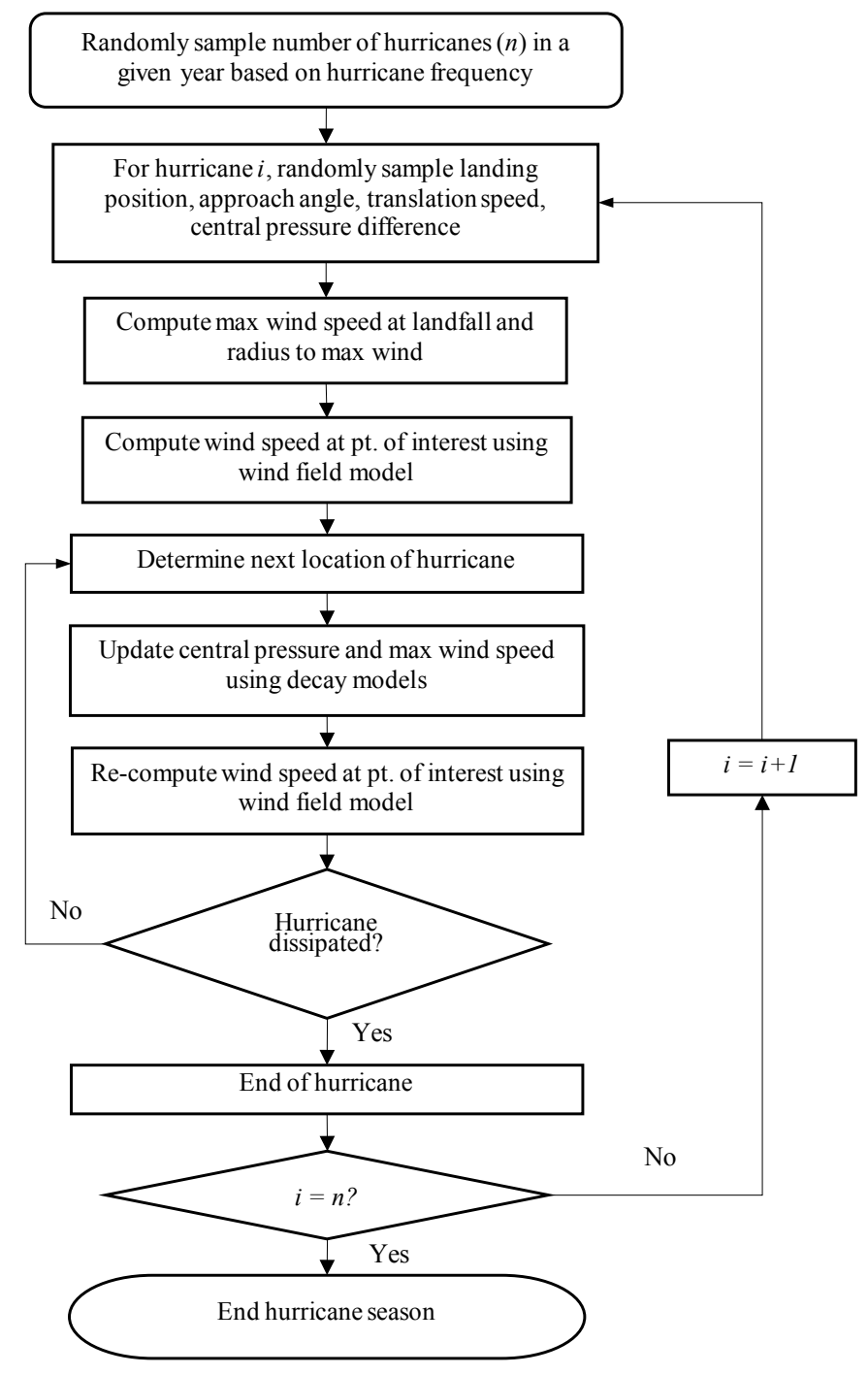

Figure 4: Hurricane simulation model flowchart [39]

For the chosen location of the case study used in this paper which is in Florida, the parameters for the hurricane simulation are obtained from Xu and Brown [38] and Huang et al. [40] based on historical records from the North Atlantic Hurricane Data Base (HURDAT) and are shown in Table 1. Note that hurricanes landing in all four regions 
of Florida (southeast, northeast, southwest, and northeast) are considered in the hurricane simulation model. For each simulated hurricane, the rise in central pressure after landfall which leads to decrease in intensity is modeled using the model developed by Vickery et al. [41]. Maximum wind speed decay after landfall due to friction and reduction in moisture is modeled using the KD9 model developed by Kaplan and DeMaria [42]. The radius to maximum wind, which defines the size of the hurricane, is calculated using the model developed in FEMA [43].

The spatial variation of gradient wind speed at each time step for each hurricane is modeled using the wind field model developed by Holland [44]. The gradient wind speed is converted to surface and then 3-sec gust wind speed using factors of 0.8 and 1.287 , respectively $[38,45,46]$. Note that the hurricane simulation model described above has been validated by the authors in Salman and Li [39] using wind speeds from ASCE-7 [47] which is the basis for calculating the design wind speed for structures in the U.S.

Table 1: Statistics of hurricane simulation parameters for different regions of Florida [39]

\begin{tabular}{|c|c|c|c|c|c|}
\hline \multirow[t]{2}{*}{ Variable } & \multirow[t]{2}{*}{ Distribution } & \multicolumn{4}{|c|}{ Distribution parameters } \\
\hline & & Southeast & Northeast & Southwest & Northwest \\
\hline Annual frequency, $\lambda$ & Poisson & 0.2 & 0.039 & 0.1871 & 0.297 \\
\hline $\begin{array}{l}\text { Approach angle, } \theta \\
\text { (degrees) }\end{array}$ & Bi-normal & $\begin{array}{c}\mu_{1}=310 \\
\sigma_{1}=30 \\
\mu_{2}=35 \\
\sigma_{2}=15 \\
a_{1}=0.9\end{array}$ & $\begin{array}{c}\mu_{1}=345 \\
\sigma_{1}=5 \\
\mu_{2}=285 \\
\sigma_{2}=10 \\
a_{1}=0.5\end{array}$ & $\begin{array}{c}\mu_{1}=40 \\
\sigma_{1}=25 \\
\mu_{2}=300 \\
\sigma_{2}=30 \\
a_{1}=0.63\end{array}$ & $\begin{array}{c}\mu_{1}=35 \\
\sigma_{1}=25 \\
\mu_{2}=295 \\
\sigma_{2}=40 \\
a_{1}=0.5\end{array}$ \\
\hline $\begin{array}{l}\text { Central pressure } \\
\text { difference }\end{array}$ & Weibull & \multicolumn{2}{|c|}{$\begin{array}{c}u=64.831 \\
\alpha=3.465\end{array}$} & \multicolumn{2}{|c|}{$\begin{array}{c}u=42.751 \\
\alpha=3.929\end{array}$} \\
\hline Translation velocity & Lognormal & \multicolumn{4}{|c|}{$\begin{array}{c}\lambda=2.3-0.00275 \theta \\
\zeta=0.3\end{array}$} \\
\hline
\end{tabular}

There is a great deal of uncertainty in long-term climate prediction. One source of such uncertainty is the level of greenhouse gas emission. The climate at the end of the $21^{\text {st }}$ century, for example, will depend on measures taken or lack of to reduce the level of greenhouse gas emission by that time. Consequently, the best way to approach longterm risk assessment considering the potential impact of climate change is through a scenario-based approach. The Intergovernmental Panel on Climate Change (IPCC), for example, uses four greenhouse gas representative concentration pathways (RCPs) determined based on their radiative forcing at the end of the $21^{\text {st }}$ century [10]. The impact of the four scenarios on hurricane patterns has been studied over the years (e.g. Knutson et al. [48], Mudd et al. [49], Bender et al. [50]). The maximum increase in intensity and frequency of hurricanes in the literature is $40 \%$ and $35 \%$, respectively $[51,52]$. Hence, for the purpose of demonstrating the proposed framework, two climate scenarios will be considered: (i) baseline scenario, i.e., no change in intensity and frequency of hurricanes, and (ii) climate change scenario with $40 \%$ and $35 \%$ increase in hurricane intensity and frequency, respectively at the end of the $21^{\text {st }}$ century.

Increase in frequency is modeled by increasing the Poisson parameter which models the annual frequency of occurrence of hurricanes as shown in Table 1. Increase in intensity is modeled by altering the central pressure of the 
hurricanes. Note that both central pressure and wind speed are a measure of hurricane intensity. However, FEMA [43] demonstrated that central pressure is a better measure of intensity than wind speed. This is because the errors associated with the measurement of wind speed are far greater than those associated with the measurement of central pressure. While considerable inter- and intra-decadal variation in frequency and intensity of hurricanes exists, it is assumed here that the change in both frequency and intensity is linear from the start of the analysis, which is assumed to be 2010 in this case, to the end of the $21^{\text {st }}$ century as suggested in [53] and [54].

200,000 hurricanes years are simulated under the no climate change scenario as well as the assumed climate change scenario at the end of the $21^{\text {st }}$ century. The Weibull distribution was found to fit the maximum annual hurricane wind speeds from the simulation [39]. Hence, time-dependent probability density function (PDF) of the maximum annual hurricane wind speed, $f_{v}(v, t)$, in Equation (1) is modeled by the Weibull distribution which is given by Equation (11):

$$
f_{v}(v, t)=\frac{\alpha(t)}{u(t)}\left(\frac{v}{u(t)}\right)^{\alpha-1} \exp \left[-\left(\frac{v}{u(t)}\right) \alpha(t)\right]
$$

where $v$ is the wind speed, and $u(t)$ and $\alpha(t)$ are the parameters of the Weibull distribution. The parameters of the Weibull distribution are calculated using MATLAB by fitting the distribution to the annual maximum wind speed data. The hazard curves for the baseline and climate change scenarios for a location on the east coast of Florida which will be the location of the case study in this paper are plotted in Fig. 5. It can be seen from the figure that the 50-year return period wind speed, which is the design basis wind speed for distribution poles, increased from $54 \mathrm{~m} / \mathrm{s}$ for the baseline scenario to $61 \mathrm{~m} / \mathrm{s}$ for the assumed climate change scenario.

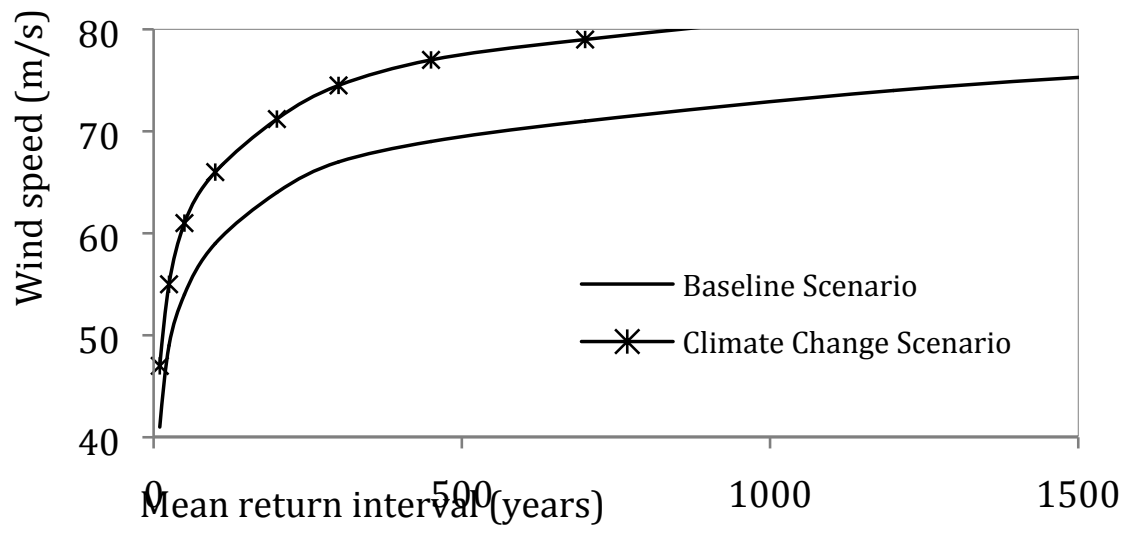

Figure 5: Hazard curves for different climate scenarios

\subsection{Network Performance}

For electric power systems, models of performance measure can range from purely topological-based models to complex alternating current (AC) power flow models. Topological- or connectivity-based models only consider the manner in which system components are arranged (topology) to describe the behavior of the system. Physical 
constraints that govern power flow within the system is ignored. Power flow-based models, on the other hand, take into account the physics of power flow, power capacity limits of components and other engineering details of the system [55].

Topological-based models have two main advantages: (i) they are computationally efficient especially for complex systems or in a case where system performance under various scenarios is desired, and (ii) significantly less data about a system is required to evaluate reliability. While power flow-based models provide more accurate description of system performance, they are computationally complex [55-59]. Furthermore, detail information about engineering properties of system components is required for such an analysis. Since the aim of this research is to focus on distribution poles which define the topology of the system, a topological-based performance measure is adopted herein.

Considering the lateral lines in a distribution system as the load points, a simple network performance measure can be obtained using the weighted reliabilities of system components. The system reliability is thus given by Equation (12) $[60,61]$ :

$$
R_{S}=1-\sum_{i=1}^{N} Q_{i} \frac{C_{i}}{C}
$$

where $Q_{i}$ is the accessibility of the $i$ th lateral lines which is defined as the probability that power is not delivered to the $i$ th lateral line; $C_{i}$ is the load served by $i$ th lateral line $(\mathrm{kVA}, \mathrm{kW}$, or number of customers); $C$ is the total load served by the system ( $\mathrm{kVA}, \mathrm{kW}$, or number of customers); and $N$ is the total number of load points in the system. $Q_{i}$ is evaluated based on power flow, i.e., the probability that power is not delivered to a lateral line depends on the probability of failure of all lines upstream. The probability of failure of a line is evaluated using Equation (13) based on the method developed by Taras et al. [62]:

$$
P_{I}=P_{i} \cdot\left\{2 P_{a}-P_{a}^{2}\right\}
$$

where $P_{i}$ is the probability of failure of a central pole and $P_{a}$ is the probability of failure of an adjacent pole conditional on the failure of the central pole. The conditional probability of failure of the adjacent poles is evaluated by increasing their applied load by $50 \%$ to account for load sharing after the failure of the central pole. Equation (13) is applied to each pole in a line and each line is modeled as a series system. As such, the probability of failure of a line increases as the number of poles increases, which will in turn decrease overall system performance.

\section{Maintenance Strategies: Impact and Optimization}

\subsection{Description of Maintenance Strategies}

Maintenance in the context of power distribution systems can be broadly divided into corrective and preventive maintenance. Corrective maintenance involves replacement of poles after failure in this case. Replacement can be triggered by two reasons: (i) due to failure of a pole caused by hurricane wind, and/or (ii) due to pole strength falling 
below a specified strength as a result of decay. Hence, failure here is defined as either exceeding the limit state in Equation (2) or the pole strength falling below a specified level. Failed poles t due to hurricane wind effect are assumed to be replaced with poles of the same class. The second reason for pole replacement depends on industry practice or guideline. In the U.S., NESC [63] recommends the replacement or reinforcement of poles when their strength falls below $67 \%$ of the initial strength. It is assumed that poles that reach the strength threshold are identified and replaced or reinforced during network inspections.

Preventive maintenance involves measures taken to slow down decay or improve the strength of a decayed pole in order to prolong its service life. These measures include using chemical treatments (pentachlorophenol, Osmoplastics, creosote, copper naphthenate, chromated copper arsenate etc.) and strengthening using fiber-reinforced polymers (FRP) or steel. Preventive maintenance measures can help to reduce overall maintenance cost and revenue loss by reducing the probability of failure of components, which also leads to improvement in system reliability as well. Preventive maintenance can be time-based, condition-based, or a combination of both.

\subsubsection{Time-based preventive maintenance}

Time-based preventive maintenance of utility poles is usually carried out at fixed intervals. Inspection intervals vary depending on utility company policy and can range from 3 to 6 for some companies and up to 8 years for others [2, 3]. The vast majority of inspection methods in the U.S. involve a combination of visual inspection, sounding with a hammer, and boring with a drill [3]. Other methods include using a Shigometer and sonic devices. These methods have uncertainties associated with them, which are not considered in this research. During an inspection, the remaining strength of poles is ascertained based on which decision is made whether to do nothing, apply treatment, reinforce the pole, or replace it. Time-based preventive maintenance is appropriate for components with a welldefined ageing process. It can, however, lead to the uneconomical use of resources as maintenance actions are carried out without regard to the condition of components.

The most common time-based preventive maintenance for utility poles is chemical treatment. If chemical treatment is carried out, it is assumed that decay is temporarily halted and a new time lag is added to the progress of the decay. At the end of the new time lag, decay resumes with the same rate pre-treatment. The chemical treatment considered in this research is the use of Osmoplastic which is an external diffusing chemical barrier. In a survey of 261 utility companies in the U.S., Mankowski et al. [3] reported that a majority of the respondents, over $40 \%$, reported using Osmoplastic for external decay control. The new lag time added by applying Osmoplastic is taken as 5 years [25].

\subsubsection{Condition-based preventive maintenance}

Condition-based preventive maintenance is carried out based on the estimate of component condition which in this case is the extent of decay. For wood poles, condition-based maintenance can be devised based on a strength-time plot such as the one shown in Fig. 3. Maintenance action can be delayed for new poles due to the time lag before the initiation of decay. Inspection interval can also be extended after the application of chemical treatment or strengthening of poles. 
The condition-based maintenance strategy considered in this research is the use of fiber-reinforced polymers (FRP) alone and in combination with chemical treatment. FRP have become one of the most common materials proposed for repair and strengthening of aged or damaged structural timber components such as beams, piles, and bridge components. Studies have shown that the use of FRP can significantly improve the strength of aged or damaged components and have advantages such as minimum installation time and high strength-to-weight ratio [64-66]. As such, the use of FRP seems to be a promising repair method for decayed wood poles. Saafi and Asa [24] studied the effectiveness of using an in situ wet layup FRP in strengthening in-service wood distribution poles. The strengthening method involved installing an FRP jacket of length 3 times the diameter of the pole around the decayed area of the pole at the groundline. Field tests were carried out on 30-year-old class 4 southern pine poles and structurally intact poles were used for comparison. The poles were tested in a cantilever bending following the procedure by ANSI [67] for wooden pole testing. It was noted that in all cases, failure occurred at or near the groundline. The results of the field tests from Saafi and Asa [24] are summarized in Table 2.

Table 2: Effect of FRP on strength of class 4 southern pine poles

\begin{tabular}{lllccc}
\hline Pole group & Properties & Pole condition & $\begin{array}{c}\text { Max stress at } \\
\text { failure (MPa) }\end{array}$ & $\begin{array}{c}\text { FRP } \\
\text { contribution } \\
(\mathrm{MPa})\end{array}$ & $\begin{array}{c}\text { \% of initial } \\
\text { strength at failure }\end{array}$ \\
\hline \multirow{3}{*}{ P1 } & $D=295 \mathrm{~mm}$ & Undamaged & 80 & 24 & 100 \\
& $L_{a}=14.63 \mathrm{~m}$ & Damaged & 47 & & 58 \\
& & Repaired & 71 & & 89 \\
P2 & $D=281 \mathrm{~mm}$ & Undamaged & 80 & 27 & 100 \\
& $L_{a}=13.106 \mathrm{~m}$ & Damaged & 43 & & 53 \\
& & Repaired & 70 & 25 & 100 \\
P3 & $D=270 \mathrm{~mm}$ & Undamaged & 77 & & 52 \\
& $L_{a}=11.582 \mathrm{~m}$ & Damaged & 40 & 65 & 85 \\
\hline \hline
\end{tabular}

$D$ is diameter at ground level and $L_{a}$ is lever arm (force application point to ground line).

It can be seen from Table 2 that the 30 -year-old damaged poles have a strength that is less than $67 \%$ of the initial strength which by NESC [63] requirement should be replaced. The application of FRP restored between $85 \%$ and $89 \%$ of the initial strength. Note that all the damaged poles in Table 2 are 30 -year-old poles. However, in this research, the repair using FRP will not necessarily be made when the poles are 30 years old. Hence, it is necessary to determine the contribution of FRP to strength regardless of age. It can be seen from Table 2 that the FRP added 24 MPa, 27 $\mathrm{MPa}$, and $25 \mathrm{MPa}$ to the strength of P1, P2, and P3, respectively. Therefore, for the purpose of demonstrating the proposed framework, it is assumed that repair using FRP will add 30\% of the initial maximum strength (i.e., $80 \mathrm{MPa}$ $\times 30 \%=24 \mathrm{MPa}$ ) to the strength of the repaired pole irrespective of the time of repair. It is acknowledged that the level of improvement in strength due to repair by FRP will depend on factors such as the type of FRP used and how it is installed, among others. Hence, in this research, it is assumed that the FRP and installation method from [24] are used. 
It is assumed that after the installation of FRP, the underlying wood continues to decay with the same rate prior to installation. It is possible that the FRP jacket will affect the rate of decay by affecting factors such as moisture content and oxygen level. However, due to lack of data, it is assumed here that the nature of the FRP-wood interface has no effect on decay rate. Little research has been carried out to investigate the deterioration of strength with time of FRP especially when used for repair of distribution poles. There is, however, some evidence, though inconclusive, that wood decay fungi can affect the strength of FRP overtime [68]. It is assumed in this research that the strength of the FRP will deteriorate due to fungal attack and other environmental factors with a rate that is half the deterioration rate of the wood [24].

Fig. 6 shows the impact of both chemical treatment and FRP repair on the service life of poles. If no action is taken against decay, it can be seen from the figure that the strength of the pole will fall below $67 \%$ of the initial strength at around 32 years at which point it is expected to be replaced according to NESC [63] requirement. For the purpose of plotting Fig. 6, it is assumed that chemical treatment is carried out every 10 years. It is also assumed that the FRP is installed at 30 years just before the strength of the pole falls below the NESC threshold. It can be seen that chemical treatment and FRP increased the service life of the pole from 32 years to 57 and 68 years, respectively, corresponding to about $78 \%$ and $113 \%$ increase. Fig. 6 also shows the service life when both chemical treatment and FRP repair are combined. In this case, chemical treatment is carried out for the first 50 years which is close to the time the treated pole is to be replaced and then the pole is repaired using FRP and the chemical treatment is stopped. It can be seen that combining the two methods increased the service life of the pole from 32 years to about 88 years, which implies an increase of about $175 \%$.

Based on the observation of Fig. 6 and the assumption that chemical treatment completely stops decay for five years, a potential condition-based strategy is to delay the start of chemical treatment until later years and then apply it every 5 years. Another possible strategy is to apply chemical treatment at the early life of the pole every 5 years for few cycles and stop. This might be more advantageous than waiting to treat the pole in later years because in this case the onset of decay is delayed rather than temporarily stopped. All these possible maintenance actions (and their respective costs) justify the implementation of optimization procedures aiming to reduce costs and failure risks. 


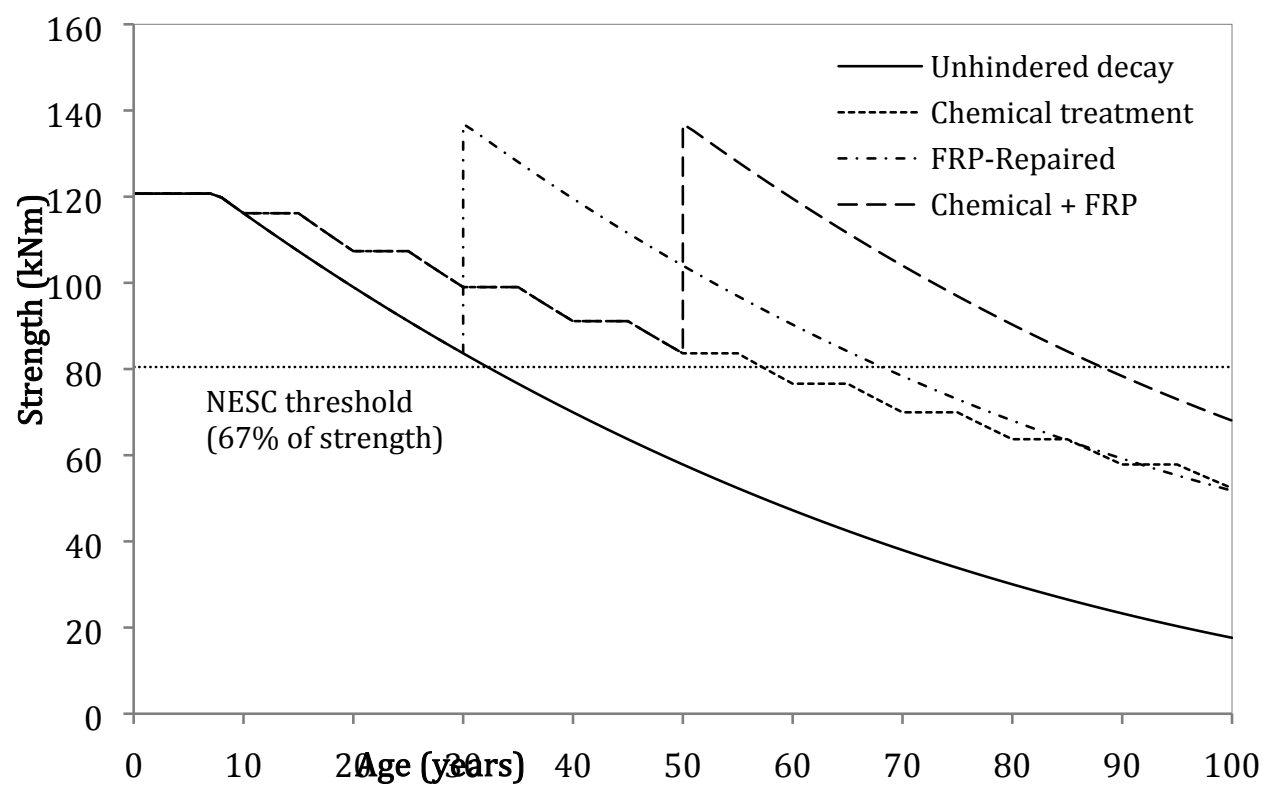

Figure 6: Service life comparison

\subsection{Maintenance Optimization}

Deregulation, scarcity of resources, increasing demand for higher levels of reliability, and pricing concerns are forcing utility companies to come up with methodologies that will guide decision making on how resources are allocated to various projects and maintenance policies. Optimization techniques can be employed to guide decision making concerning resource allocation and maintenance policy selection. The aim of maintenance optimization is to select a strategy from a pool of maintenance policies that satisfies prescribed objective functions such as minimizing cost and/or maximizing performance. In this research, optimization based on cost, service life, and system performance will be carried out. These objective functions are first optimized individually and after simultaneously using a multi-objective optimization approach. In all cases, the decision variable is the time to implement the preventive maintenance strategy.

\subsubsection{Cost}

The objective here is to determine the optimum repair (or replacement) age of the poles that will minimize the total maintenance cost (preventive and corrective) over a period of time. The repair, in this case, is the installment of FRP to untreated and periodically chemically-treated poles. This is achieved by employing renewal theory which aims to determine the optimum renewal point (installment of FRP) that minimizes the expected cost $C(T)$ experienced during $[0, T]$. General discussion of renewal theory can be found in [69] and [70]. For an infinite time span, the objective function is expressed as the expected total cost per unit time as shown in Equation (14) [70, 71]:

$$
C(T)=\lim _{L \rightarrow \infty} \frac{C(T ; L)}{L}=\frac{\text { Expected total cycle cost }}{\text { Expected cycle length }}=\frac{E[C(T)]}{E(T)}
$$


where $C(T)$ is the annual total cycle cost; $T$ is the cycle length or the time between renewals; $L$ is the time span considered for the analysis. In this case, the expected total cycle cost, $E[C(T)]$, consist of the cost of preventive maintenance $\left(C_{p}\right)$, and the cost of corrective maintenance $\left(C_{c}\right)$ whereby $C_{c}>C_{p}$. This is because in many situations, the failure of a pole during operation is costly and even dangerous. In a case where a component is characterized by decay or wear, which leads to increase in failure rate, it might be more cost-effective to repair or replace it before it deteriorates too much. In the case of a failure, $C_{c}$ includes the cost of pole replacement under emergency conditions, revenue loss due to power outage, and in some cases, regulatory penalties. The total cycle cost is given by Equation (15):

$$
E[C(T)]=C_{p} R_{s}(T)+C_{c} F(T)
$$

where $F(T)$ is the cumulative distribution function (CDF) of the service life of the pole, which models the probability that failure will occur before renewal, and $R_{S}(T)$ is the survival function of the pole which is equal to $[1-F(T)]$. The distribution of the service life of the poles is assumed to follow a Weibull distribution with a COV of $25 \%$ [21]. The mean value of the service life is found based on the decay rate as the age in which the pole strength fall below $67 \%$ of the initial strength. The expected cycle length, $E(T)$, is given by Equation (16):

$$
E(T)=\int_{0}^{T} R_{s}(t) d t=\int_{0}^{T}[1-F(t)] d t
$$

The objective function in Equation (14) is then given by:

$$
C(T)=\frac{C_{p} R_{s}(T)+C_{c} F(T)}{\int_{0}^{T} R_{s}(t) d t}
$$

To find the optimum renewal (repair or replacement) time, we seek to minimize Equation (17) as given by Equation (18), which is then simplified to Equation (19):

$$
\begin{gathered}
\frac{d[C(T)]}{d T}=0 \\
\frac{C_{p}}{C_{c}-C_{p}}=\left[h(T) \int_{0}^{T} R_{s}(t) d t\right]-F(T)
\end{gathered}
$$

where $h(T)$ is the hazard function or failure rate. A solution exists for Equation (19) if $h(T)$ is continuous and strictly increasing which holds true for the Weibull distribution [70]. For the Weibull distribution, $h(T)$ is given by Equation (21):

$$
h(T)=\frac{k}{w}\left(\frac{T}{w}\right) k-1
$$

where $k$ and $w$ are the parameters of the Weibull distribution, which are computed using the method of moments. In Equation (19), $C_{c}-C_{p}$ is the additional cost incurred if corrective action is carried out rather than preventive action. The ratio on the left side of Equation (19) can, therefore, be used to decide whether or not it is advantageous 
to carry out preventive maintenance as will be seen later in the case study results. The cost-based optimization formulation writes:

$$
\left\{\begin{array}{c}
\underset{T_{m}}{\operatorname{argmin}} E\left[C\left(T, T_{m}\right), R_{o}, D_{o}, r(t)\right] \\
\quad \text { Subject to: } T_{m} \in\left[0, T_{t}\right]
\end{array}\right.
$$

where $T_{m}$ is the optimal time of implementing preventive maintenance strategy; $R_{o}$ is the initial pole strength; $D_{o}$ is the initial diameter of the pole; $r(t)$ is the decay rate of the pole which is a function of time; and $T_{t}$ is the target service life (e.g., $T_{t}=50$ years).

\subsubsection{Service life}

In this case, a constraint optimization with the objective of maximizing the service life of the poles is performed. The optimization is formulated as follows:

$$
\left\{\begin{array}{c}
\underset{T_{m}}{\operatorname{argmax}} T_{S}\left[R_{o}, D_{o}, r(t), r_{F R P}, T_{m}\right] \\
\text { Subject to: } T_{m} \leq T_{N E S C}
\end{array}\right.
$$

where $T_{S}$ is the service life of the pole; $r_{F R P}$ is the decay rate of the FRP; and $T_{N E S C}$ is the time it takes the strength of the pole to reach the NESC strength threshold (time for pole strength to fall to $2 / 3$ of initial strength). The optimization problem is solved numerically by evaluating the service life of the poles with preventive maintenance performed at a different point in time or intervals as will be seen in the case study. The constraint of $T_{m} \leq T_{N E S C}$ is satisfied if the preventive maintenance is carried before the strength of the pole falls below $2 / 3$ of the initial strength due to decay. Hence, the maintenance scheduling period in this case is from the time of pole installation to $T_{N E S C}$.

\subsubsection{System performance}

The objective here is to find the optimal FRP repair age for untreated and chemically-treated poles based on system performance considering NESC strength requirement constraint. The NESC strength constraint can be satisfied if the repair is carried out before the strength of a pole falls below $2 / 3$ of the initial strength, $R_{o}$. As the system performance varies with time due to decay and increase in hurricane hazard level due to climate change, the minimum system performance over a specified period is considered in this formulation for the optimization. Indeed, it is considered that FRP repair is implemented at the minimum system performance time. The optimization is formulated as follows:

$$
\left\{\begin{array}{c}
\underset{T_{m}}{\operatorname{argmax}} R_{S_{\min }}\left[F_{R}(t), f_{v}(t), P_{I}, C_{i}, C, T_{m}\right] \\
\\
\text { Subject to: } T_{m} \leq T_{N E S C}
\end{array}\right.
$$


where $R_{S_{\min }}$ is the minimum system performance over a selected period; $F_{R}(t)$ is the fragility of the poles which is a function of time due to decay; $f_{v}(t)$ is the probability density function of hurricane wind speed which is a function of time due to climate change impact; $P_{I}$ is the probability of failure of a line in the system; and $C_{i}$ and $C$ are the loads served by the $i$ th lateral line and the system, respectively. The optimization problem is solved numerically by evaluating the minimum system performance over a selected period for various values of $T_{m}$. Maintenance optimization with respect to system performance leads to a reliability-centered maintenance (RCM). This is an improvement over condition-based maintenance as it considers both the probability of component failure as well as the system impact should failure occur.

The optimization problems involving service life and system performance involve non-linear objective functions that cannot be stated explicitly as functions of the decision variable (optimum preventive maintenance time, $T_{m}$ ). Moreover, the time-dependent nature of some of the variables involved in the optimization further complicates the solution. As such, numerical exhaustive search method is used to solve the problems. This is feasible because there is only one decision variable, and the constraint that $T_{m} \leq T_{N E S C}$ in both cases implies the interval in which the optimum lies is finite. Additionally, $T_{m}$ is an integer, which also reduces the solution space.

\subsubsection{Multi-objective optimization}

In this case, a multi-objective optimization involving all the three objectives is performed. As the results of the individual solution of the three objectives are not identical, as will be seen later in the case study, a multi-objective optimization of the three objectives has to involve a trade-off. Therefore, the aim here is to find a Pareto optimum solution using one of the common methods of multi-objective optimization. In cases where the decision maker has to prioritize some objectives over others, hierarchical methods such as the utility function method (weighting function method) and the lexicographic method can be used [72]. In this case, however, the global criterion method is used as it does not require ranking or assigning weighting factors to the objectives. The global criterion method aims to minimize a function which is a measure of how close an obtained solution is to the ideal solutions of the objectives. The multi-objective optimization is formulated as follows [73]:

$$
\left\{\begin{array}{c}
\underset{T_{m}}{\operatorname{argmin}} F\left(T_{m}\right)=\left[\sum_{i=1}^{k}\left|\frac{f_{i}\left(T_{o_{i}}\right)-f_{i}\left(T_{m}\right)}{f_{i}\left(T_{o_{i}}\right)}\right| p\right]^{1 / p} \\
\text { Subject to: } T_{m} \leq T_{N E S C} \text { and } T_{m} \in\left[0, T_{t}\right]
\end{array}\right.
$$

where $k$ is the number of objectives; $f_{i}$ is the $i$ th objective function; $T_{o_{i}}$ is the ideal or optimal solution for the $i$ th objective; and $p$ is a constant. Recommended values of $p$ are 1 and 2 [73-76]. Other values can also be used. For the cost optimization, the objective is to minimize the annual total cycle cost given by Equation (17). Note that even 
though the NESC strength requirement is not explicitly stated as a constraint in the cost optimization, the assumption that the mean service life of the poles used to solve Equations (17) and (19) is the time it takes for the pole strength to equal to $2 / 3$ of the initial strength indirectly constraint the optimal solution to ensure that the FRP repair is carried out before the pole strength falls below the NESC requirement. For the service life and system performance optimizations, the objective is to maximize the service life and the minimum system performance, respectively.

As mentioned earlier, the maintenance strategies considered in this research are chemical treatment to temporarily stop decay and use of FRP to strengthened decayed poles. Carrying out both maintenance strategies do not require service interruptions to customers. Additionally, the time to carry out the maintenance is negligible compared to the maintenance scheduling period. As such, maintenance period for each pole is not considered in the optimization formulations. It is also assumed that there is adequate manpower to carry out the maintenance actions. Hence, manpower requirement is not considered as a decision variable or a constraint in the optimization formulations.

\section{Case Study}

\subsection{Power Distribution System}

The power distribution system adopted for demonstrating the proposed framework is shown in Fig. 7 and 8 . It is the power distribution system of a virtual city called "Micropolis" developed at Texas A\&M for use in infrastructure research. Researchers have used the power system to study the potential impact of various hazards on distribution systems $[20,77,78]$. The system serves a city approximately 2 miles by 1 mile with about 5,000 residents and it is assumed to be located on the east coast of Florida, with the middle of the city located at $27.6^{\circ} \mathrm{N}$ and $80.4^{\circ} \mathrm{W}$. The city has one substation with two three-phase feeders that branched off to smaller three-phase sub-branches and singlephase laterals that deliver electricity to customers. The system serves 434 residential, 15 industrial, and 9 commercial/institutional customers including 3 schools and 3 churches [79]. Though a part of the system is originally designed as underground, it is assumed here that the entire system is overhead.

The lines are assumed to be supported by $13.7 \mathrm{~m}$ high southern pine poles with a span of $46 \mathrm{~m}$ [80]. There are an estimated 661 poles in the system. The three-phase main feeder poles are assumed to support three Aluminum Conductor Steel Reinforced (ACSR) conductor wires with diameters of $18.3 \mathrm{~mm}$ and one all-aluminum conductor (AAC) neutral wire with a diameter of $11.8 \mathrm{~mm}$. The single-phase laterals are assumed to support two ACSR conductor wires and one AAC neutral wire. Based on these configurations, the required pole sizes are found to be class 4 and 5 using the reliability-based design method in ASCE-111 [33] for the three-phase and single-phase lines, respectively. The system is assumed to be radially operated at all times. Isolator elements at the upstream of each line allow the system to be reduced to several switchable sections. For simplicity sake, customers in Micropolis are classified into 5 groups with all customers belonging to each group having a fixed average load demand throughout the year as shown in Table 3 [81].

Table 3: Load profiles for consumers across Micropolis [61] 


\begin{tabular}{ll}
\hline \hline Customer type & Consumption \\
\hline Residential & $1.5 \mathrm{~kW} / \mathrm{h}$ \\
City churches & $5 \mathrm{~kW} / \mathrm{h}$ \\
City schools & $10 \mathrm{~kW} / \mathrm{h}$ \\
Industrial (Feeder 1) & $39.4 \mathrm{~kW} / \mathrm{h}$ \\
Central business district (Feeder 2) & $10.1 \mathrm{~kW} / \mathrm{h}$ \\
\hline Feeder $\mathbf{1}$ total & $\mathbf{1 , 3 3 4 k W / h}$ \\
Feeder 2 total & $\mathbf{3 9 4 k W / h}$ \\
System total & $\mathbf{1 , 7 2 8 k W / h}$ \\
\hline \hline
\end{tabular}

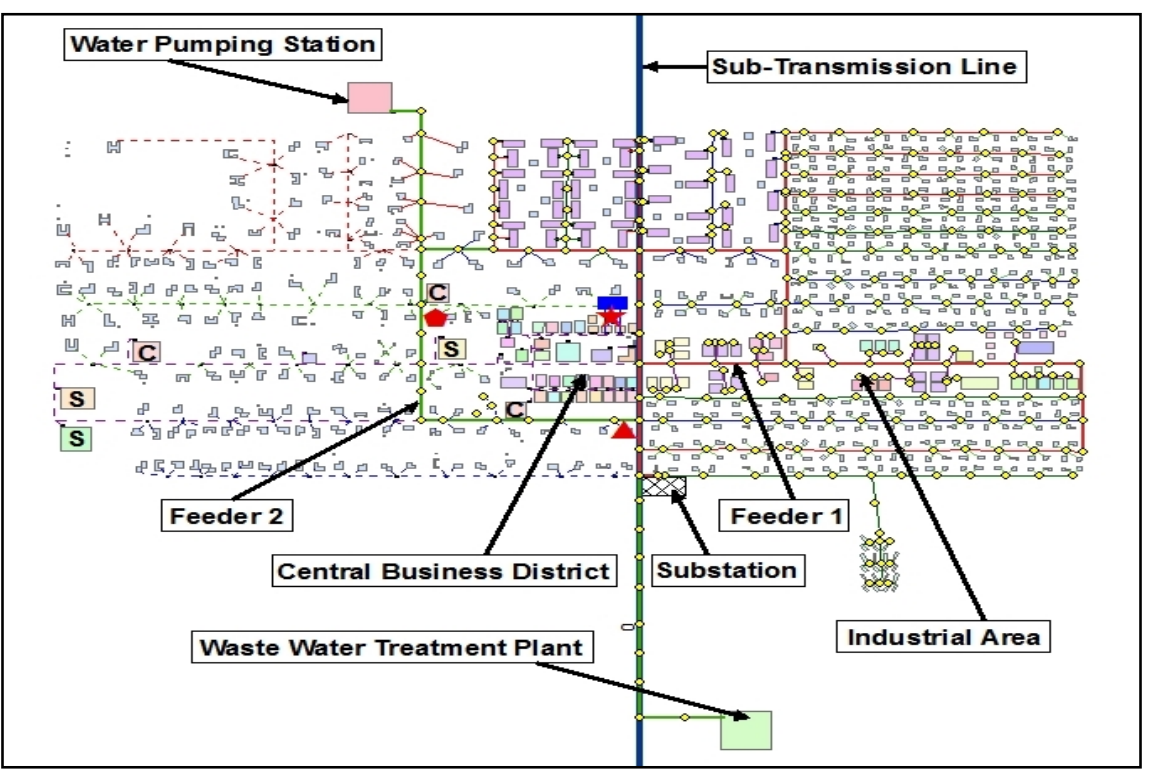

Fig. 7. Micropolis power distribution system

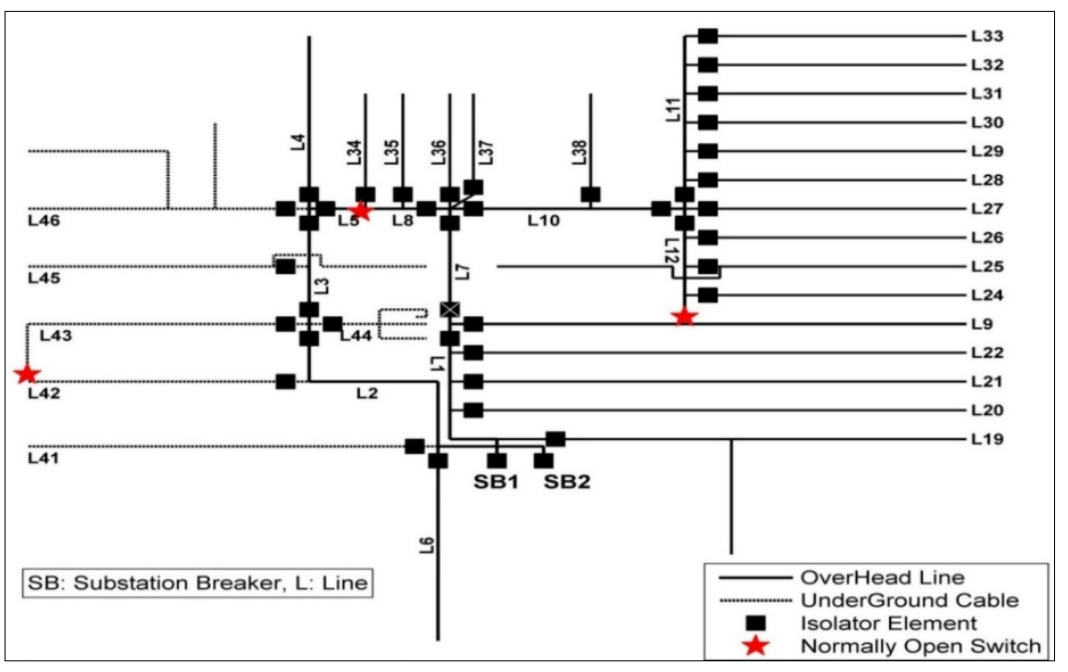

Fig. 8. Micropolis power distribution system line diagram 
As mentioned earlier, corrective maintenance here is defined as pole replacement due to failure caused by hurricane wind. The number of failed poles in a line in a given year due to hurricane winds is calculated by multiplying the annual probability of failure of the poles with the number of poles in the line. Failed poles are replaced with poles of the same class. As the city is small compared to the size of a hurricane, it is assumed that the hurricane hazard is the same for all the poles in the city. As such, the hazard curve in Fig. 5 is used for all the poles in the city.

\subsection{Optimization results}

\subsubsection{Cost}

The result of the optimization based on total maintenance cost is shown in Fig. 9 for condition-based preventive maintenance using FRP only. The cost ratio on the vertical axis is the left-hand side of Equation (20) which is the ratio of the cost of preventive maintenance to the additional cost incurred if failure were to occur. Saafi and Asa [24] estimated the cost of replacing a decayed pole to be around $\$ 10,000$ compared to the cost of repair using FRP which is about $\$ 1,500$. This means the cost ratio is about 0.18 . Based on this ratio, the optimum repair age without climate change is about 18 years which is much lower than the mean service life of 32 years estimated from Fig. 6. This implies that since the cost of repair is much less than the additional cost if failure were to occur, the best strategy is to repair the pole much earlier in its life. If decay rate changed by $\pm 20 \%$ due to climate change, the optimum repair times are 15 and 23 years which corresponds to a change of $-17 \%$ and $28 \%$, respectively, relative to the case with no climate change.

A similar analysis is also carried out for a combination of time-based preventive maintenance (chemical treatment every 10 years) and condition-based preventive maintenance (FRP repair at end of service life of chemically-treated wood). Time-based chemical treatment is assumed to be carried out every 10 years as most utilities have regular inspection programs of 8-12 years [82]. The result of the cost optimization is shown in Fig. 10. For a cost ratio of 0.18 , the optimum repair time is 32 years without climate change compared to 18 years if there is no chemical treatment. In this case, however, the cost of the chemical treatment should be considered in decision making. Similar curves can be plotted for time-based chemical treatment intervals other than 10 years. Note that the results in Fig. 9 and 10 are for class 4 poles. Class 5 poles show similar trends. 


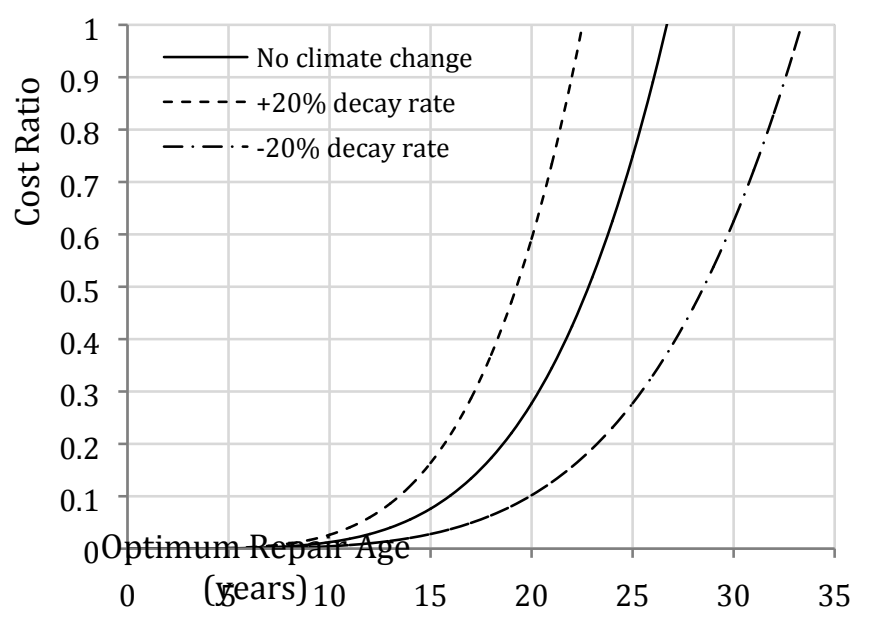

Figure 9: Optimum FRP repair age for untreated poles based on cost

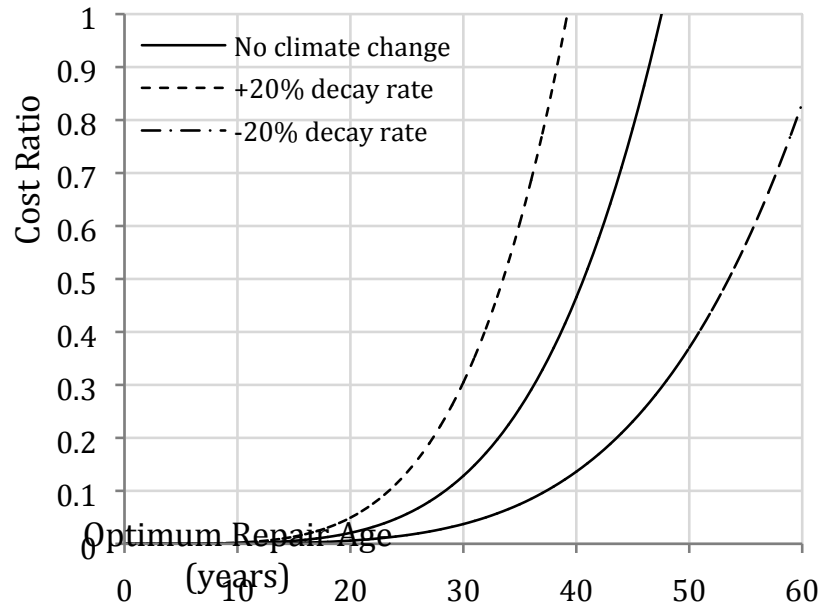

Figure 10: Optimum FRP repair age for periodically chemically-treated poles based on cost

\subsubsection{Service life}

Fig. 11 shows the relationship between time of FRP installment and service life. It can be seen from the figure that service life increases as the age at which the FRP repair is carried out increases. Note that if only FRP repair is considered, then it has to be carried out at or before the time the strength of the pole falls below $67 \%$ of its initial strength which is around 32 years. Based on Fig. 11, it can be argued that in this case, the optimum time of installing the FRP is when the pole reached the end of its service life as defined by NESC. This is contrary to the results in the previous section where the optimum FRP installation age based on cost optimization is less than the service life of the pole. In comparison to the previous case, delaying maintenance operations until the end of the lifetime increases the failure risk.

Fig. 12 shows a plot of the annual probability of failure of a pole with no FRP repair and FRP repair at 5, 15, and 30 years. The annual probability of failure of a new pole without FRP is around $2 \%$. The annual probabilities of failure of the pole at 90 years without FRP repair and with FRP repair carried out at 0, 5, 15, and 30 years are 40\%, 26\%, $24 \%, 23 \%$, and $22 \%$, respectively. This implies that the FRP drastically reduced the component risk with the highest reduction realized for FRP installed in later years. It can also be inferred from Fig. 12 that the age of FRP repair has little impact on decreasing component risk. For example, at 50 years, the annual probabilities of failure of a pole with FRP installed at $0,5,15$, and 30 years are $7 \%, 6.6 \%, 6.4 \%$, and $6 \%$, respectively. However, delaying FRP installment implies the pole will have a higher probability of failure before the installment. For example, the probability of failure of the pole at 30 years is $6 \%$. If it is desired to keep the component risk below $6 \%$, then the FRP repair must be carried out before the pole is 30 years old. 


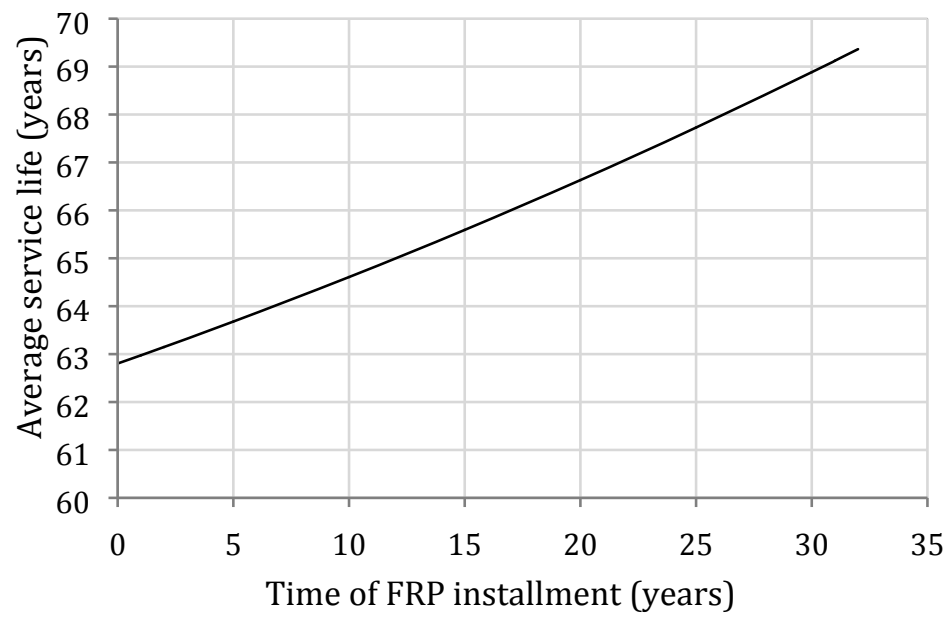

Figure 11: Optimum FRP installment time for class 4 poles

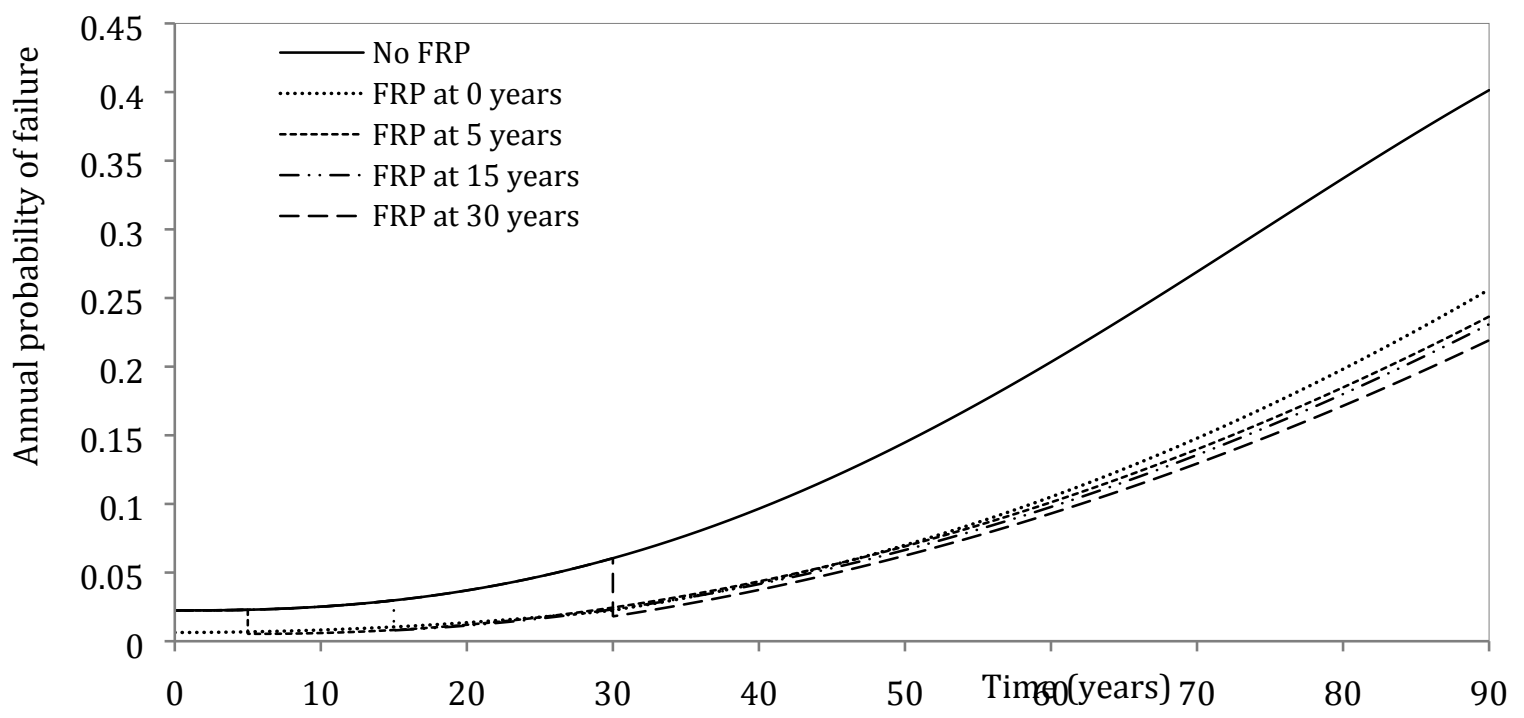

Figure 12: Annual probability of failure of class 4 poles

Fig. 13 shows a plot of chemical treatment interval vs service life. Note that only constant time interval is considered in the plot. It can be seen that the service life decreases as the interval increases. Because of the assumption that chemical treatment completely stops decay for five years after each application, the optimum interval to maximize service life is 5 years. This implies that theoretically, the pole will last forever if it is treated every 5 years. This, of course, is not the case as realistically, the chemical treatment may only slow down the decay rate. Additionally, chemical treatment every 5 years may not be the optimum maintenance strategy in terms of cost as applying a chemical treatment to all poles in a large network every 5 years is an expensive endeavor. 
Based on the slope of the plots that shows the pole strength degradation in Fig. 6 and the results from Fig. 13, it can be deduced that the optimum strategy for the combination of chemical treatment and FRP repair is to install the FRP at the end of the service life of the chemically-treated pole.

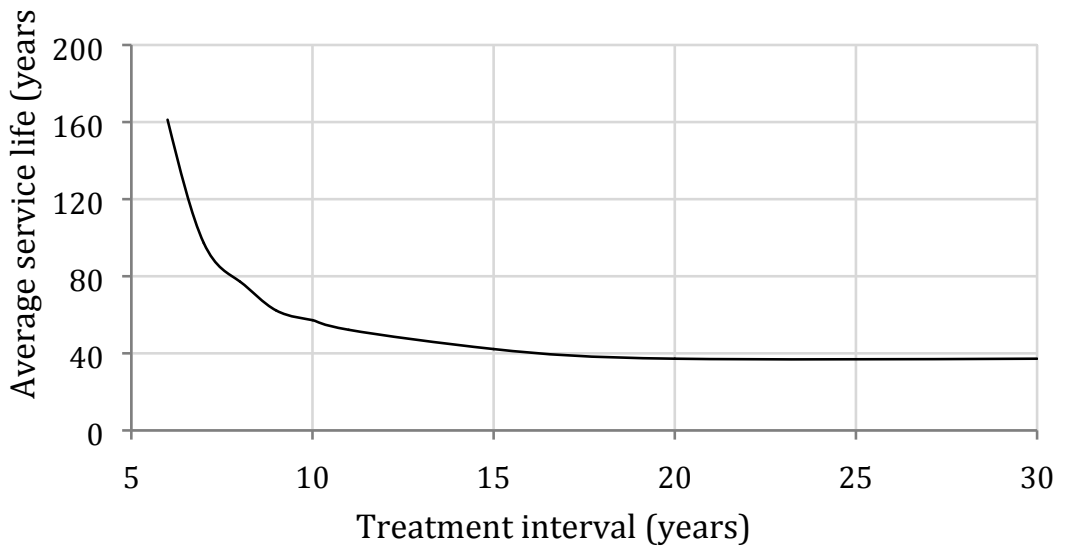

Figure 13: Optimum interval for chemical treatment

\subsubsection{System performance}

Fig. 14 shows the optimization result based on minimum system performance. As the aim here is to find the optimum time for first repair using FRP, the period over which minimum system performance is evaluated is taken as 50 years to allow comparison. This is because, within this period, the strength of FRP-repaired poles will not fall below $2 / 3$ of the initial strength of the poles which will lead to the replacement of the repaired poles. The plots in Fig. 14 only considers climate change impact on hurricane hazard. Similar plots can also be made for cases where climate change affects decay. From Fig. 14(a), the optimal repair time for FRP repair only is 27 years with and without climate change. The minimum system performance, however, decreased from $58 \%$ to $43 \%$ due to climate change impact. Note that the system performance at age 0 with all new poles is $88 \%$ while the minimum system performance over 50 years with neither chemical treatment nor FRP repair is $7 \%$.

Fig. 14(b) shows the optimization result for a combination of chemical treatment and FRP repair. Chemical treatment is assumed to be applied every 10 years. Therefore, the minimum time of FRP repair is 15 years which is at the end of the effect of the first chemical treatment. It is assumed that the periodic chemical treatment is stopped once the FRP is installed. The optimal FRP repair age for the chemically-treated poles is 30 years with and without climate change. Fig. 14 can also be used to find the optimal repair time to maximize service life for a given minimum system performance constraint. For example, in the case of FRP repair only with no climate change impact, if it is desired that the system performance should not fall below 55\% over the considered period, the repair can be carried at either around 24 years or 29 years. However, based on the results of Fig. 11, the repair should be carried out at 29 years to maximize the service life of the poles.

The results in Fig. 14 can also be used to determine the FRP repair time if minimum system performance is constraint to a certain value. For example, if it is desired to constraint the minimum system performance to $\geq 70 \%$ over the 50 - 
year period considered in the case of chemical treatment and FRP repair with no climate change impact, then the FRP repair has to be carried out between approximately 20 and 32 years as can be seen from Fig. 14(b).

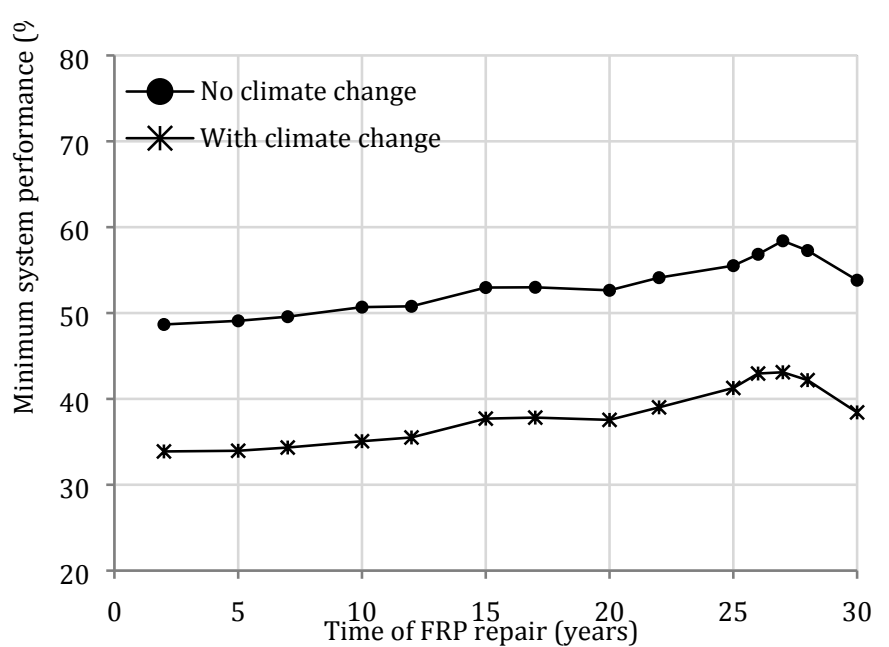

(a)

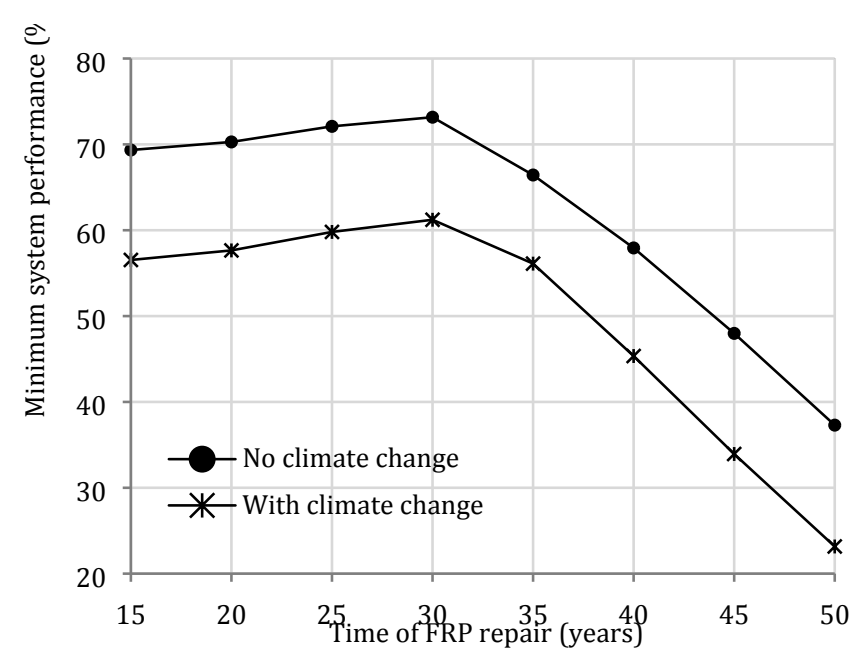

(b)

Figure 14: Optimization result based on average system performance (a) FRP repair only (b) Chemical treatment and FRP repair

Alternatively, the optimization can be formulated based on average system performance over the considered period the result of which is shown in Fig. 15. It can be seen that the average system performance decreases slowly as the age of FRP repair increases. Consequently, an optimal repair time could be estimated by defining a threshold average system performance. Optimal repair times obtained by this formulation, however, will be very sensitive to this threshold value. In addition, the results based on average system performance do not consider the minimum system performance values that could lead to system failure, and therefore, they compromise system safety.
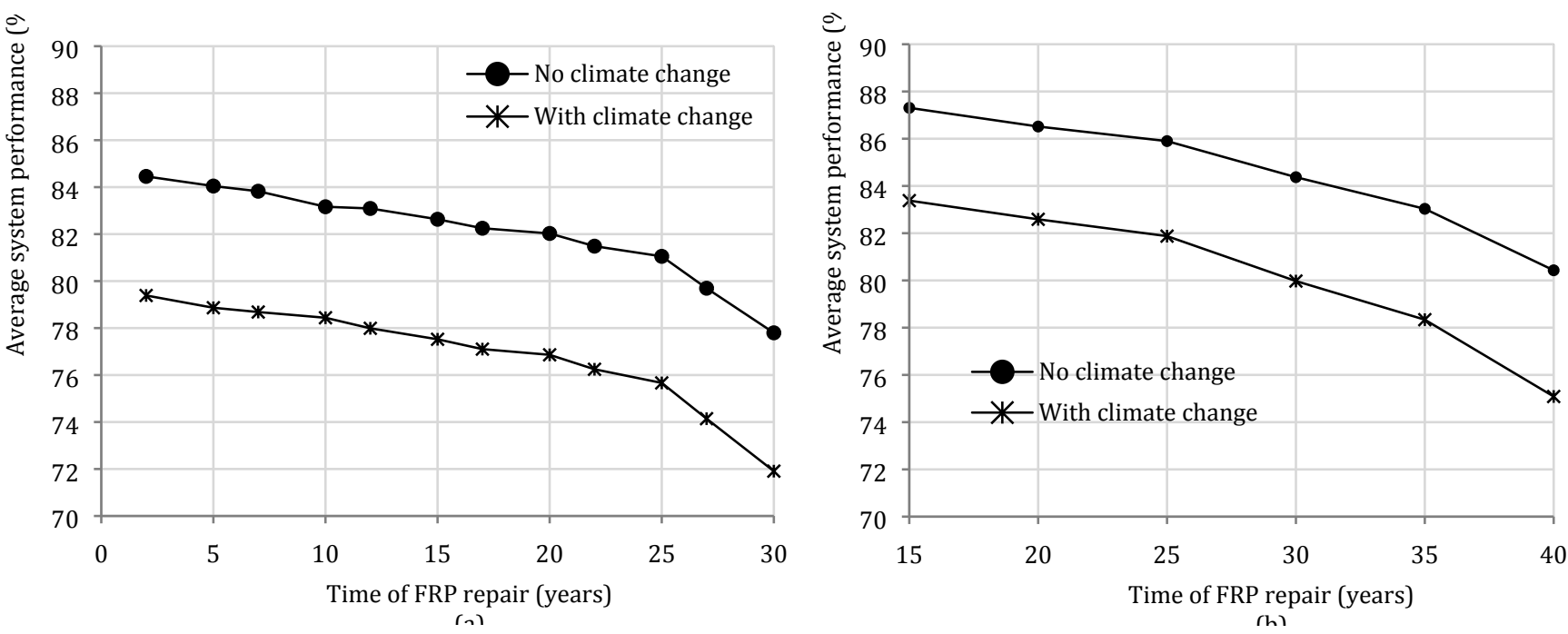

Figure 15: Optimization result based on average system performance (a) FRP repair only (b) Chemical treatment and FRP repair 


\subsubsection{Multi-objective optimization results}

The results of the three individual optimization formulations are first compared in Table 4 based on minimum system performance over 50 years and cost ratio (Figs. 9 and 10). For illustrative purposes, the comparison in Table 4 is the case with no climate change impact. It is observed that each formulation proposed different FRP repair times that will be related to different costs and system performance. Although the optimal repair time for chemical treatment + FRP for the service life formulation is outside the 50-year period considered in Fig. 14(b), these results are presented for comparative purposes.

Table 4: Comparison of optimization results

\begin{tabular}{lcccccc}
\hline \hline $\begin{array}{l}\text { Optimization } \\
\text { formulation } \\
\text { basis }\end{array}$ & \multicolumn{2}{c}{ Optimal FRP repair time (years) } & $\begin{array}{c}\text { Minimum system performance } \\
\text { over 50 years (\%) }\end{array}$ & \multicolumn{2}{c}{ Cost ratio } \\
\cline { 2 - 7 } & $\begin{array}{c}\text { FRP repair } \\
\text { only }\end{array}$ & $\begin{array}{c}\text { Chemical } \\
\text { treatment + FRP } \\
\text { repair }\end{array}$ & $\begin{array}{c}\text { FRP repair } \\
\text { only }\end{array}$ & $\begin{array}{c}\text { Chemical } \\
\text { treatment + FRP } \\
\text { repair }\end{array}$ & $\begin{array}{c}\text { FRP repair } \\
\text { only }\end{array}$ & $\begin{array}{c}\text { Chemical } \\
\text { treatment + FRP } \\
\text { repair }\end{array}$ \\
\hline $\begin{array}{l}\text { Cost } \\
\text { Service life }\end{array}$ & 18 & 32 & 53 & 73 & 0.18 & 0.18 \\
$\begin{array}{l}\text { System } \\
\text { performance }\end{array}$ & 27 & 57 & 51 & 37 & 2.20 & 2.20 \\
\hline \hline
\end{tabular}

Comparing the results based on minimum system performance, the formulations based on cost and service life will lead to experiencing lower system performance within the considered period for the FRP repair only case. For the case of chemical treatment and FRP repair, the minimum system performance of the cost and system performance formulation are similar because their optimum optimal repair times are very close. For both FRP repair only and FRP + chemical treatment, the optimal repair time based on service life gives the lowest system performance over the period. This result is expected because their corresponding repair times are larger than the other formulations, and therefore, latter FRP implementation increases failure risks.

Comparing the results based on cost ratio of each formulation, it is noted that the cost ratios corresponding to service life and system performance formulations are greater than the value obtained for the cost formulation when only FRP repair is considered. This implies that latter repair based on service life or system performance will, in this case, increase failure risk and therefore the cost of corrective maintenance. The optimal repair times based on service life and system performance formulations will only be optimal in terms of cost if the cost of the FRP repair outweighs the additional cost incurred due to failure as indicated by the cost ratio being greater than 1 . For the case of chemical treatment and FRP repair, the solution provided by the system performance formulation provides the minimum cost ratio. This means that this repair strategy will be more cost-effective if preventive and corrective maintenance costs are similar for all formulations.

The results of the multi-objective optimization are shown in Fig. 16 using different values of $p$ in Equation (24). For the case of FRP repair only (Fig. 16(a)), the optimal FRP repair age considering all three objectives is 18 years for $p=1$, which is exactly the same as the solution for the cost optimization as shown in Table 4 . For $2 \leq p \leq 4$, the 
optimal repair time is 21 years. For all values of $p$, the result of the multi-objective optimization is closer to the result of the cost optimization. This is because the relative deviation of the cost function for any value of $T_{m}$ from its ideal solution is higher than that of the service life and system performance functions. That is, the cost function is more sensitive to the variation of the time of FRP repair, $T_{m}$. In situations where service life and system performance are more important than cost, relative weights can be assigned to the objectives. The results of the case with chemical treatment and FRP repair, plotted in Fig. 16(b), show similar trend. For $p=1$, the optimum is exactly the same as the solution for the cost optimization. For $2 \leq p \leq 4$, the optimal repair time is 35 years. 5 -year increment is used due to effect of the chemical treatment.
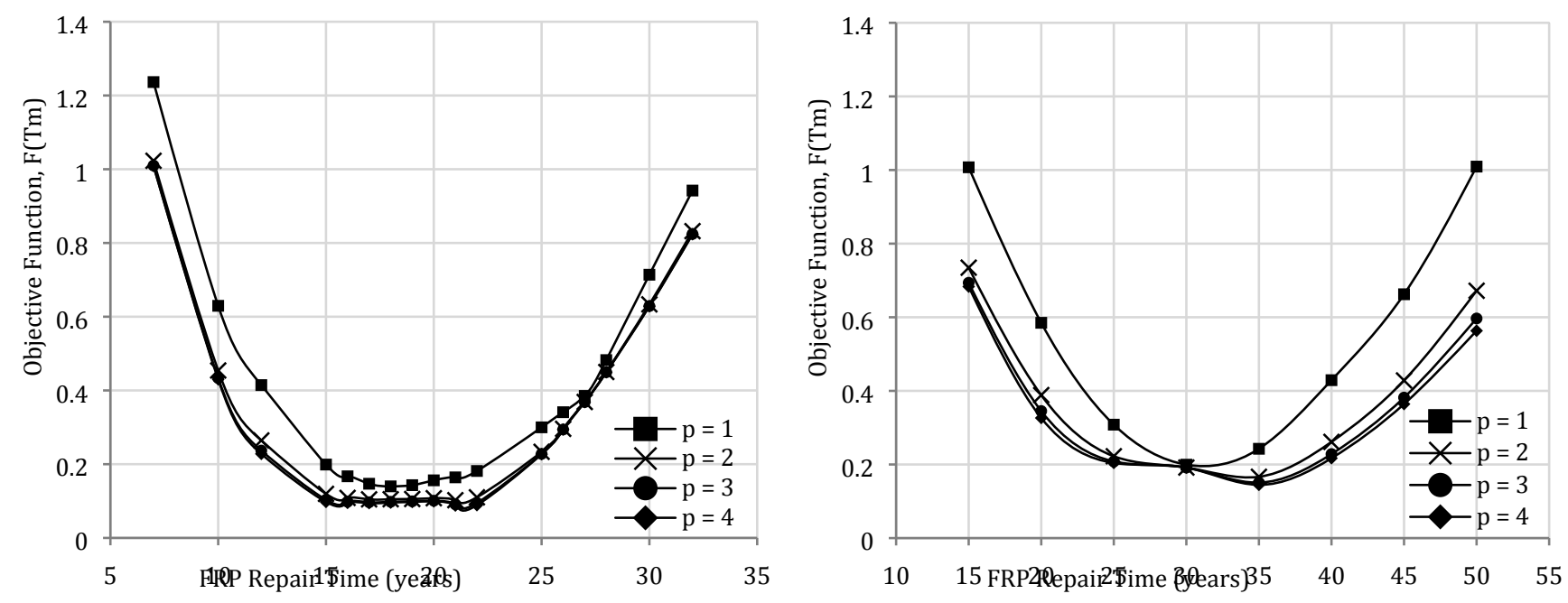

Figure 16: Multi-objective optimization result (a) FRP repair only (b) Chemical treatment and FRP repair

\section{Discussion and Future Work}

The Micropolis power distribution system considered to demonstrate the framework has one substation and two feeders as mentioned earlier. However, some distribution systems, especially those located in large urban areas, can have several substations with looped or networked topology comprising tens of feeders and hundreds or thousands of sectionalizing switches. This will make computing system performance using the probabilistic method described in this paper tedious. In such a case, the optimization based on cost and service life will be easier to perform. Alternatively, the optimization can be performed by taking the component performance as the constraint rather than system performance. The component performance will then be quantified in terms of annual probability of failure of the poles due to hurricane winds calculated using Equation (1). In such a case, Fig. 12 can be used to find the time of FRP repair for a given annual probability of failure constraint.

The Uncertainty in the structural reliability of the poles was incorporated directly in the component risk assessment through fragility analysis and hurricane simulation using Monte Carlo simulation. This includes the uncertainty related to the initial strength of the poles, decay parameters, decay testing variation, decay model, and hurricane 
occurrence and its parameters as described in Section 2.1. The main source of uncertainty in the models is the decay of the wood poles. Wood decay is a complex phenomenon that depends on various material, environmental, and soil factors. While the decay model used considered uncertainty in the decay rate, the uncertainty related to the initiation of decay is not considered. Hence, the decay model is a deterministic rather than a probabilistic model. Future research will focus on a probabilistic decay model that incorporates uncertainty related to decay initiation and inspection technique and results. Uncertainty related to the impact of climate change on hurricane hazard stems from the level of greenhouse gas emission and epistemic uncertainty related to climate modeling. In this research, a scenario that represents high impact of climate change on hurricane intensity and frequency was considered to demonstrate the proposed framework with the aim of modelling the worst impact. The presented maintenance optimization framework can be used to model different levels of climate change impact scenarios to account for uncertainty in future hurricane patterns.

Since pole replacement is often expensive, resource intensive, and operationally disruptive, preventive maintenance strategies can be used to extend the service life of poles. To determine their cost-effectiveness, however, a more detailed life cycle cost analysis should be performed and is a topic of future study. It is likely that periodic maintenance and repair using FRP will be cheaper than replacement considering the fact that replacement of a damaged pole includes the cost of a new pole, cost of removing and disposing of the existing pole, and cost of transferring conductors to the new pole. A life cycle cost analysis of preventive maintenance strategies should also consider the cost of replacing poles that have reached the NESC threshold for strength. This cost can be substantive especially in large networks with aged components or in networks situated in environments conducive to decay causing organisms.

\section{Conclusions}

Long-term risk-based asset management of electric power distribution systems subjected to hurricane hazard requires the consideration of realistic exposure conditions such as climate change impact and deterioration of components. This paper presented a framework for optimal maintenance of wood poles considering service life, maintenance cost, and system performance as objectives. The framework was demonstrated using a virtual city as a case study and considering periodic chemical treatment of the poles and repair of decayed poles using FRP.

From the result of the case study, it can be concluded that the optimal age of repair of the wood poles depends on the objective. In all cases, the optimization based on service life resulted in the highest optimal FRP repair time. This implies that if it is desired to maximize the service life of the poles, repair at a later age is advantageous. However, this will result in higher probability of failure of the poles which will reduce the system performance measure. On the other hand, if repair actions are performed based on minimum system performance, the repair strategy could be costly. A preliminary study comparing the results for these three formulations indicated that the cost-based one provides, in general, cost-effective repair solutions; however, solutions based on system performance formulation could improve the cost-effectiveness in some cases without compromising system safety. The results also show that the impact of periodic chemical treatment on optimal FRP repair time depends on the selected objective. Chemical 
treatment significantly increased the optimal FRP repair time based on cost and service life optimization. It, however, had little impact on the optimal FRP repair time when system performance is considered. The optimal FRP repair time based on multi-objective optimization is closer to the optimal based on cost optimization; nevertheless, the results could vary depending on priorities. For instance, a decision maker can assign weight or rank the various objectives in order of importance to solve the multi-objective optimization using one of the hierarchical optimization techniques. This way, the multi-objective optimal will be closer to the optimal of the most important objective.

The results of the case study also show that the potential impact of climate change on hurricane hazard and decay rate can significantly affect maintenance planning. For example, a $20 \%$ change in decay rate due to climate change can alter the optimum repair time for cost optimization by as much as $28 \%$. The impact of climate change was also shown to significantly impact system performance. The minimum system performance over a period of 50 years decreased from $58 \%$ to $43 \%$ due to the impact of climate change on hurricane hazard. However, climate change did not affect the optimal FRP repair time in the case of optimization based on system performance objective. As such, long-term asset management for components that are vulnerable to hurricane hazard should incorporate climate change impact. It is important, however, to highlight that the results of the case study are based on a specific climate change scenario and wood decay model which were selected to demonstrate the proposed framework. Using different environmental and climate conditions could lead to different conclusions.

\section{Acknowledgments}

The research described in this paper was supported, in part, by the National Science Foundation (NSF) Catalyzing New International Collaborations Program, and Infrastructure Management and Extreme Events Program under Grant No. NSF-1050443. This support is gratefully acknowledged. However, the writers take sole responsibility for the views expressed in this paper, which may not represent the position of the NSF or their respective institutions.

\section{References}

[1] Crews, K. and A. Horrigan. (2000). Strength assessment of timber utility poles in Australia. New Zealand Timber Design Journal, 9(2).

[2] Ryan, P.C., et al. (2014). Reliability assessment of power pole infrastructure incorporating deterioration and network maintenance. Reliability Engineering \& System Safety, 132, 261-273.

[3] Mankowski, M., E. Hansen, and J. Morrell. (2002). Wood pole purchasing, inspection, and maintenance: A survey of utility practices. Forest products journal, 52(11/12), 43.

[4] Shafieezadeh, A., et al. (2014). Fragility Assessment of Wood Poles in Power Distribution Networks against Extreme Wind Hazards. Bridges, 10, 9780784412626.074.

[5] Li, Y., et al. (2005, 23-25 Oct. 2005). Degradation-path model for wood pole asset management. Paper presented at the Proceedings of the 37th Annual North American Power Symposium, 2005. .

[6] FP\&LC. (2006). Technical Report: Post Hurricane Wilma Engineering Analysis: KEMA, Inc.

[7] Larsen, T., et al. (1996). Impact of Hurricane Andrew on performance, interaction, and recovery of lifelines: EQE International.

[8] USDOE. (2005). Florida State's Energy Emergency Response to the 2004 Hurricanes: US Department of Energy - Office of Electricity Delivery and Energy Reliability.

[9] Zamuda, C., et al. (2013). US Energy Sector Vulnerabilities to Climate Change and Extreme Weather: DTIC Document.

[10] IPCC. (2013). Summary for Policymakers. In: Climate Change 2013: The Physical Science Basis. Contribution of Working Group I to the Fifth Assessment Report of the Intergovernmental Panel on Climate Change [Stocker, T.F., D. Qin, G.-K. Plattner, M. Tignor, S.K. Allen, J. Boschung, A. Nauels, Y. Xia, V. Bex and P.M. Midgley (eds.)]. Cambridge University Press, Cambridge, UK and New York, NY, USA.

[11] Gutowski, W., et al. (2008). Causes of observed changes in extremes and projections of future changes: TR Karl, et al.(eds.), US Climate Change Science Program, Weather and Climate Extremes in a Changing Climate, Regions of Focus: North America, Hawaii, Caribbean and US Pacific Islands.

[12] Hilber, P., et al. (2007). Multiobjective optimization applied to maintenance policy for electrical networks. IEEE Transactions on Power Systems, 22(4), 1675-1682. 
[13] Lehtonen, M. (2006). On the optimal strategies of condition monitoring and maintenance allocation in distribution systems. Paper presented at the Probabilistic Methods Applied to Power Systems, 2006. PMAPS 2006. International Conference on.

[14] Abbasi, E., M. Fotuhi-Firuzabad, and A. Abiri-Jahromi. (2009). Risk based maintenance optimization of overhead distribution networks utilizing priority based dynamic programming. Paper presented at the 2009 IEEE Power \& Energy Society General Meeting.

[15] Sittithumwat, A., F. Soudi, and K. Tomsovic. (2004). Optimal allocation of distribution maintenance resources with limited information. Electric power systems research, 68(3), 208-220.

[16] Arab, A., et al. (2016). System Hardening and Condition-Based Maintenance for Electric Power Infrastructure Under Hurricane Effects. IEEE Transactions on Reliability, PP(99), 1-14. doi:10.1109/TR.2016.2575445

[17] Winkler, J., et al. (2010). Performance assessment of topologically diverse power systems subjected to hurricane events. Reliability Engineering \& System Safety, 95(4), 323-336.

[18] Bjarnadottir, S., Y. Li, and M.G. Stewart. (2012). Hurricane risk assessment of power distribution poles considering impacts of a changing climate. Journal of Infrastructure Systems, 19(1), 12-24.

[19] Gustavsen, B. and L. Rolfseng. (2000). Simulation of wood pole replacement rate and its application to life cycle economy studies. IEEE Transactions on Power Delivery, 15(1), 300-306.

[20] Francis, R.A., et al. (2011). Probabilistic life cycle analysis model for evaluating electric power infrastructure risk mitigation investments. Climatic change, 106(1), 31-55.

[21] Datla, S. and M. Pandey. (2006). Estimation of life expectancy of wood poles in electrical distribution networks. Structural safety, 28(3), 304-319.

[22] Pierson, K. and T. Blanc. (2016). The Operational Determinants of Utility Pole Decay and Optimal Replacement in the Pacific Northwest. IEEE Transactions on Power Delivery, 31(5), 2223-2230. doi:10.1109/TPWRD.2016.2517043

[23] Salman, A.M. and Y. Li. (2016). Age-dependent fragility and life-cycle cost analysis of wood and steel power distribution poles subjected to hurricanes. Structure and Infrastructure Engineering, 12(8), 890-903.

[24] Saafi, M. and E. Asa. (2010). Extending the service life of electric distribution and transmission wooden poles using a wet layup FRP composite strengthening system. Journal of performance of constructed facilities, 24(4), 409-416.

[25] Wang, C.-H., R.H. Leicester, and M.N. Nguyen. (2008). Manual 3 - Decay in ground contact. Melbourne, Australia: Forest \& Wood Products Australia.

[26] Shafieezadeh, A., et al. (2014). Age-dependent fragility models of utility wood poles in power distribution networks against extreme wind hazards. IEEE Transactions on Power Delivery, 29(1), 131-139.

[27] ANSI-O5.1. (2002). Wood poles specifications and dimensions Washington, DC: American National Standards Institute.

[28] Wolfe, R. and R. Moody. (1997). Standard specifications for wood poles. Paper presented at the Proceedings of the 1997 Utility Pole Structures Conference and Trade Show, JJ Morrell, ed., Reno/Sparks, Nevada, Nov.

[29] Morrell, J.J. (2008). Estimated service life of wood poles. Technical Bulletin, North American Wood Pole Council, http://www. woodpoles. org/documents/TechBulletin_EstimatedServiceLifeofWoodPole_12-08. pdf (Last accessed 5 April 2013).

[30] Peel, M.C., B.L. Finlayson, and T.A. McMahon. (2007). Updated world map of the Köppen-Geiger climate classification. Hydrology and earth system sciences discussions, 4(2), 439-473.

[31] Brites, R.D., et al. (2013). Reliability analysis of a timber truss system subjected to decay. Engineering structures, 46, $184-192$.

[32] Freitas, R.R.d., J.C. Molina, and C. Calil Júnior. (2010). Mathematical model for timber decay in contact with the ground adjusted for the state of São Paulo, Brazil. Materials Research, 13(2), 151-158.

[33] ASCE-111. (2006). Reliability-based design of utility pole structures. Reston, VA: American Sociaety of Civil Engineers.

[34] ASCE-74. (1991). Guidelines for electrical transmission line structural loading. Reston, VA: American Society of Civil Engineers.

[35] Gere, J.M. and W.O. Carter. (1962). Critical buckling loads for tapered columns. ASCE -- Proceedings -- Journal of the Structural Division, 88(ST1, Part 1), 1-11.

[36] Wang, C.-h., R.H. Leicester, and M. Nguyen. (2008). Probabilistic procedure for design of untreated timber poles in-ground under attack of decay fungi. Reliability Engineering \& System Safety, 93(3), 476-481.

[37] Ellingwood, B.R. and P.B. Tekie. (1999). Wind load statistics for probability-based structural design. Journal of Structural Engineering, 125(4), 453-463.

[38] Xu, L. and R.E. Brown. (2008). A hurricane simulation method for Florida utility damage and risk assessment. Paper presented at the Power and Energy Society General Meeting-Conversion and Delivery of Electrical Energy in the 21st Century, 2008 IEEE.

[39] Salman, A.M. and Y. Li. (2016). Assessing Climate Change Impact on System Reliability of Power Distribution Systems Subjected to Hurricanes. Journal of Infrastructure Systems. doi:10.1061/(ASCE)IS.1943-555X.0000316

[40] Huang, Z., D. Rosowsky, and P. Sparks. (2001). Hurricane simulation techniques for the evaluation of wind-speeds and expected insurance losses. Journal of wind engineering and industrial aerodynamics, 89(7), 605-617.

[41] Vickery, P.J., et al. (2000). Hurricane wind field model for use in hurricane simulations. Journal of Structural Engineering, 126(10), 12031221.

[42] Kaplan, J. and M. DeMaria. (1995). A simple empirical model for predicting the decay of tropical cyclone winds after landfall. Journal of applied meteorology, 34(11), 2499-2512.

[43] FEMA. (2011). Multi-Hazard Loss Estimation Methodology, Hurricane Model: Hazus-MH 2.1 Technical Manual. Washington, DC: FEMA.

[44] Holland, G.J. (1980). An analytic model of the wind and pressure profiles in hurricanes. Monthly weather review, 108(8), $1212-1218$.

[45] Vickery, P.J., et al. (2009). Hurricane hazard modeling: The past, present, and future. Journal of Wind Engineering and Industrial Aerodynamics, 97(7), 392-405.

[46] ESDU. (1983). Strong winds in the atmospheric boundary layer. Part 1: Discrete gust speeds. London: Engineering Sciences Data Unit.

[47] ASCE-7. (2010). Minimum design loads for building and other structures: American Society of Civil Engineers, ASCE Reston Virginia. 
[48] Knutson, T.R., et al. (2010). Tropical cyclones and climate change. Nature Geoscience, 3(3), 157-163.

[49] Mudd, L., et al. (2014). Assessing climate change impact on the US East Coast hurricane hazard: temperature, frequency, and track. Natural Hazards Review, 15(3), 04014001.

[50] Bender, M.A., et al. (2010). Modeled impact of anthropogenic warming on the frequency of intense Atlantic hurricanes. Science, $327(5964), 454-458$.

[51] Staid, A., et al. (2014). Simulation of tropical cyclone impacts to the US power system under climate change scenarios. Climatic Change, 127(3-4), 535-546.

[52] Landsea, C.W., et al. (2010). Impact of Duration Thresholds on Atlantic Tropical Cyclone Counts*. Journal of Climate, 23(10), $2508-2519$.

[53] Bastidas-Arteaga, E. and M.G. Stewart. (2015). Damage risks and economic assessment of climate adaptation strategies for design of new concrete structures subject to chloride-induced corrosion. Structural Safety, 52, 40-53.

[54] Stewart, M.G., X. Wang, and G.R. Willgoose. (2014). Direct and indirect cost-and-benefit assessment of climate adaptation strategies for housing for extreme wind events in Queensland. Natural Hazards Review, 15(4), 04014008.

[55] LaRocca, S., et al. (2014). Topological performance measures as surrogates for physical flow models for risk and vulnerability analysis for electric power systems. Risk Analysis, 35(4), 608-623. doi:10.1111/risa.12281

[56] Duenas-Osorio, L. and I. Hernandez-Fajardo. (2008). Flow-based reliability assessment of infrastructure systems. Paper presented at the 14th World Conference on Earthquake Engineering (14WCEE).

[57] Kim, Y. and W.-H. Kang. (2013). Network reliability analysis of complex systems using a non-simulation-based method. Reliability Engineering \& System Safety, 110, 80-88.

[58] Cavalieri, F., et al. (2014). Models for seismic vulnerability analysis of power networks: comparative assessment. Computer-Aided Civil and Infrastructure Engineering, 29(8), 590-607.

[59] Albert, R., I. Albert, and G.L. Nakarado. (2004). Structural vulnerability of the North American power grid. Physical review E, 69(2), 025103.

[60] Volkanovski, A., M. Čepin, and B. Mavko. (2009). Application of the fault tree analysis for assessment of power system reliability. Reliability Engineering \& System Safety, 94(6), 1116-1127.

[61] Salman, A.M., Y. Li, and M.G. Stewart. (2015). Evaluating system reliability and targeted hardening strategies of power distribution systems subjected to hurricanes. Reliability Engineering \& System Safety, 144, 319-333.

[62] Taras, A., G. Ratel, and L. Chouinard. (2004). A life-cycle cost approach to the maintenance of overhead line supports. Paper presented at the Reliability and Optimization of Structural Systems: Proceedings of the 11th IFIP WG7. 5 Working Conference, Banff, Canada, 2-5 November 2003.

[63] NESC. (2002). National Electric Safety Code: Institute of Electrical and Electronics Engineers.

[64] Borri, A., M. Corradi, and A. Grazini. (2005). A method for flexural reinforcement of old wood beams with CFRP materials. Composites Part B: Engineering, 36(2), 143-153.

[65] Lopez-Anido, R., et al. (2005). Repair of wood piles using prefabricated fiber-reinforced polymer composite shells. Journal of performance of constructed facilities, 19(1), 78-87.

[66] Gentile, C. (2000). Flexural strengthening of timber bridges using FRP: MSc thesis, Univ. of Manitoba, Winnipeg, Manitoba, Canada.

[67] ANSI. (1992). Specifications and dimensions for wood poles. New York: American NAtional Standards Institute.

[68] Tascioglu, C., et al. (2003). Monitoring fungal degradation of E-glass/phenolic fiber reinforced polymer (FRP) composites used in wood reinforcement. International biodeterioration \& biodegradation, 51(3), 157-165.

[69] Smith, W.L. (1958). Renewal theory and its ramifications. Journal of the Royal Statistical Society. Series B (Methodological), $243-302$.

[70] Barlow, R.E. and F. Proschan. (1965). Mathematical Theory of Reliability. Philadelphia, PA: SIAM Publications.

[71] Ben-Daya, M., U. Kumar, and D.P. Murthy. (2016). Introduction to Maintenance Engineering: Modelling, Optimization and Management. West Sussex, U.K.: John Wiley \& Sons.

[72] Bastidas-Arteaga, E. and F. Schoefs. (2015). Sustainable maintenance and repair of RC coastal structures. Proceedings of the ICE: Maritime Engineering, 168(4), 162-173. doi:10.1680/jmaen.14.00018

[73] Chiandussi, G., et al. (2012). Comparison of multi-objective optimization methodologies for engineering applications. Computers \& Mathematics with Applications, 63(5), 912-942.

[74] Rao, S.S. (2009). Engineering optimization: theory and practice. Hoboken, New Jersey: John Wiley \& Sons.

[75] Boychuk, L. and V. Ovchinnikov. (1973). Principal methods of solution of multicriterial optimization problems (survey). Soviet Automatic Control, 6(3), 1-4.

[76] Salukvadze, M. (1974). On the existence of solutions in problems of optimization under vector-valued criteria. Journal of Optimization Theory and Applications, 13(2), 203-217.

[77] Bagchi, A., A. Sprintson, and C. Singh. (2009). Modeling the impact of fire spread on the electrical distribution network of a virtual city. Paper presented at the North American Power Symposium (NAPS), 2009.

[78] Francis, R. and B. Bekera. (2014). A metric and frameworks for resilience analysis of engineered and infrastructure systems. Reliability Engineering \& System Safety, 121, 90-103.

[79] Brumbelow, K., et al. (2007). Virtual cities for water distribution and infrastructure system research. Paper presented at the World Environmental and Water Resources Congress.

[80] Short, T.A. (2005). Electric power distribution equipment and systems: CRC press.

[81] EIA. (2013). 2012 Utility Bundled Retail Sales: U.S. Energy Information Administration.

[82] Bolin, C.A. and S.T. Smith. (2011). Life cycle assessment of pentachlorophenol-treated wooden utility poles with comparisons to steel and concrete utility poles. Renewable and Sustainable Energy Reviews, 15(5), 2475-2486. 


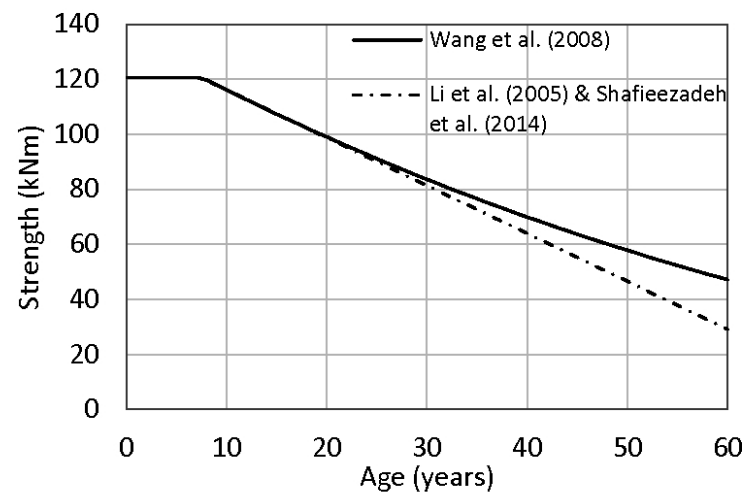




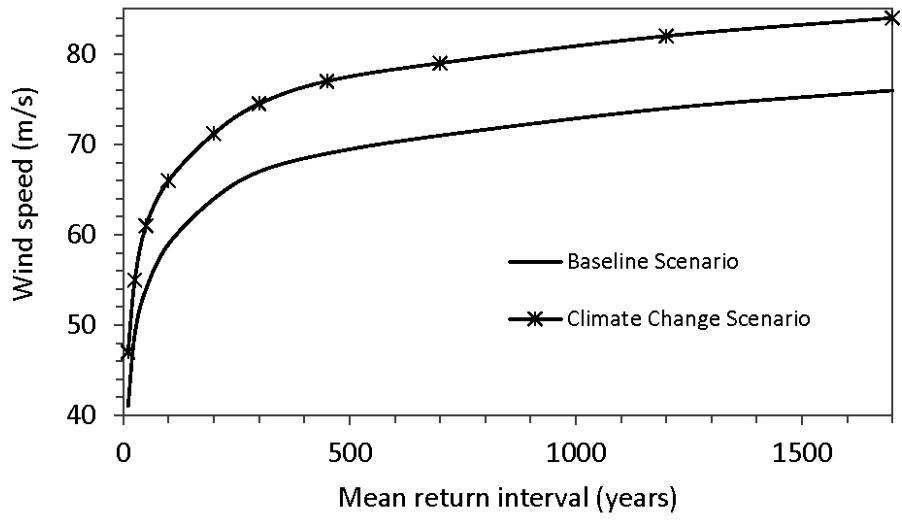




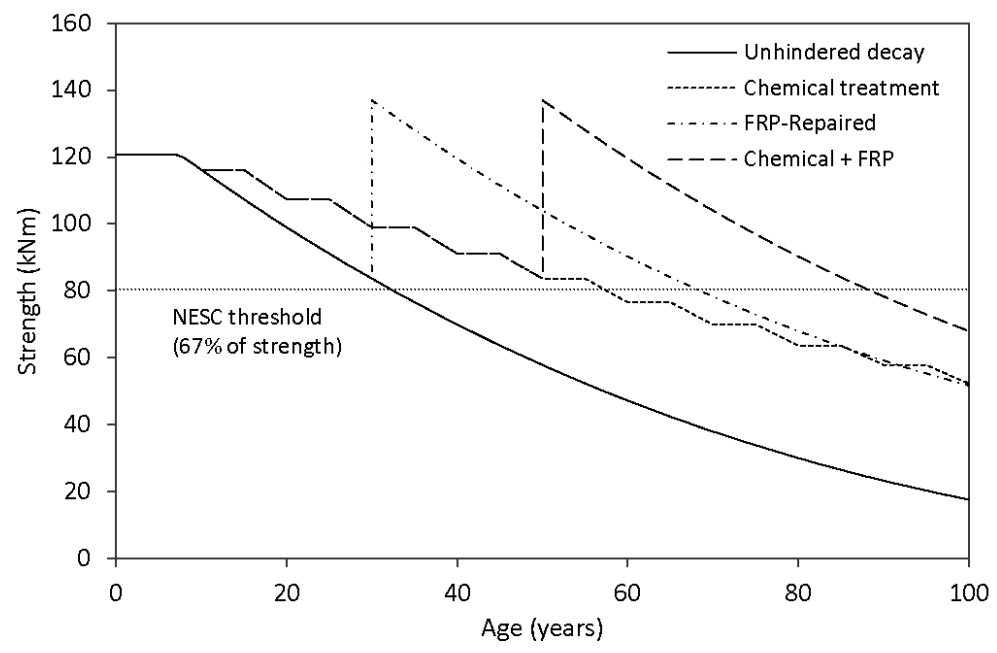




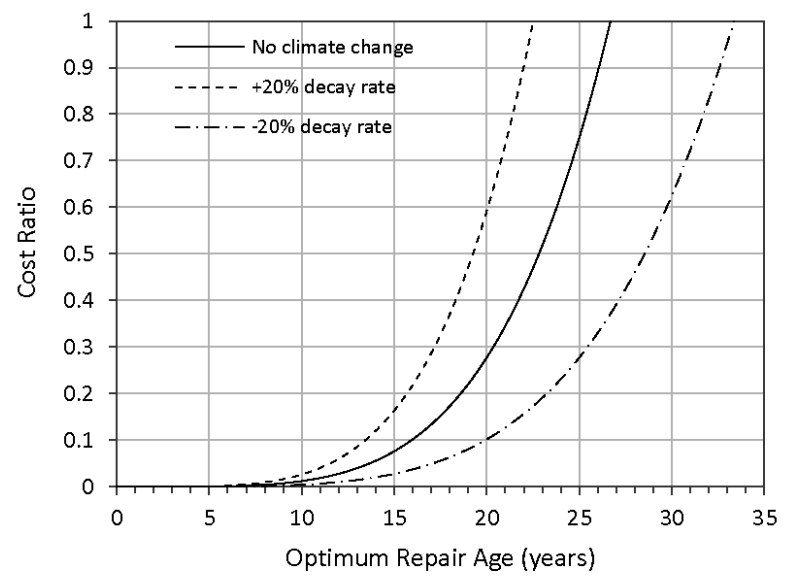




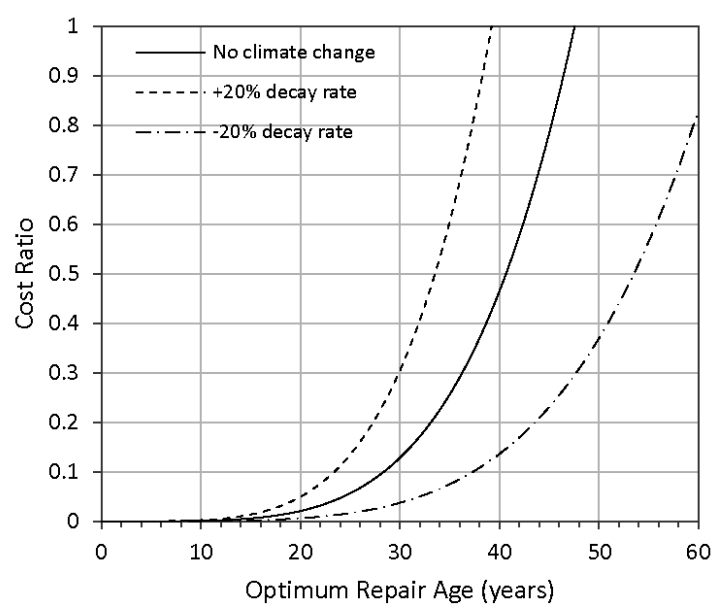




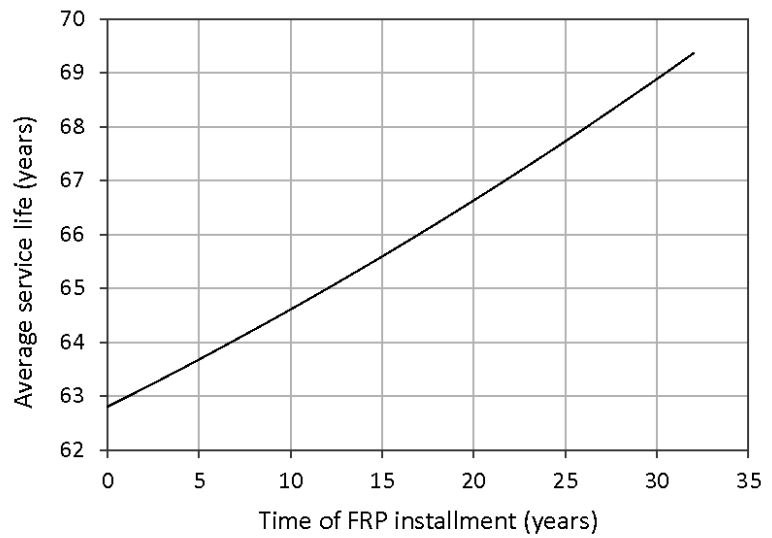




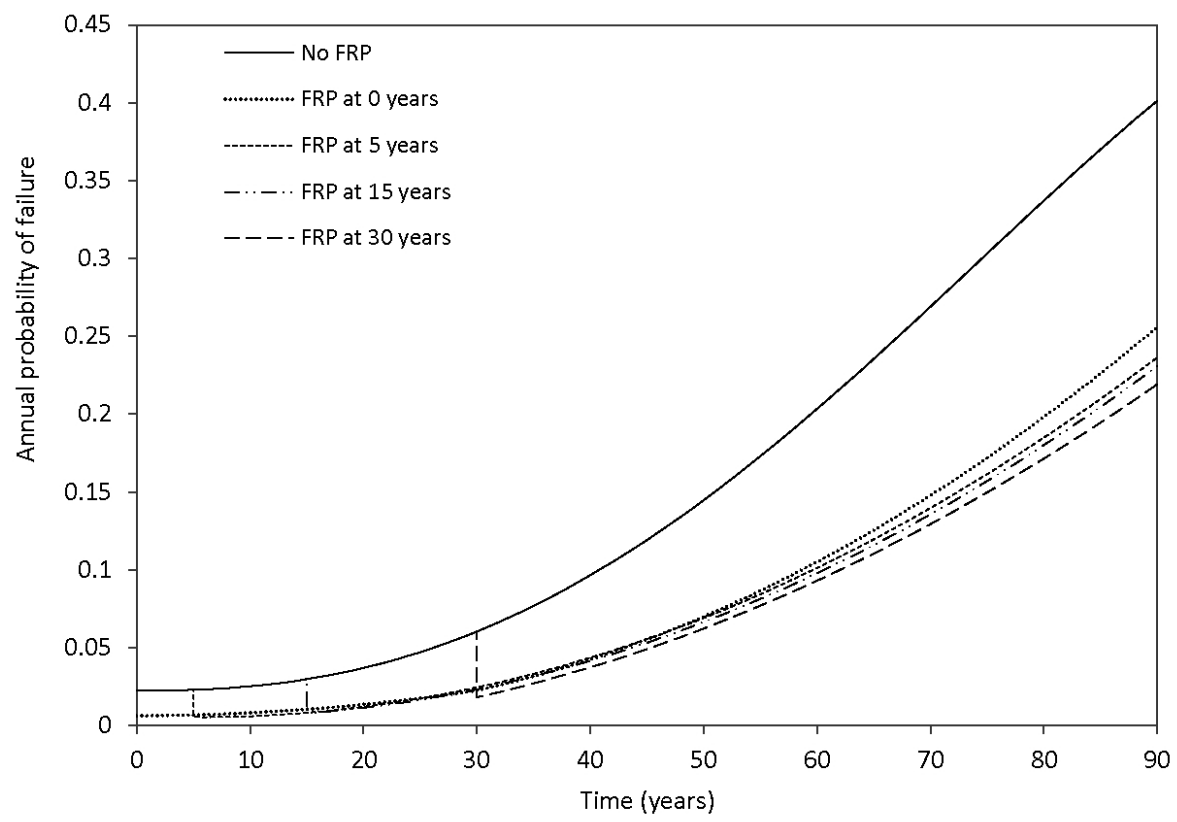




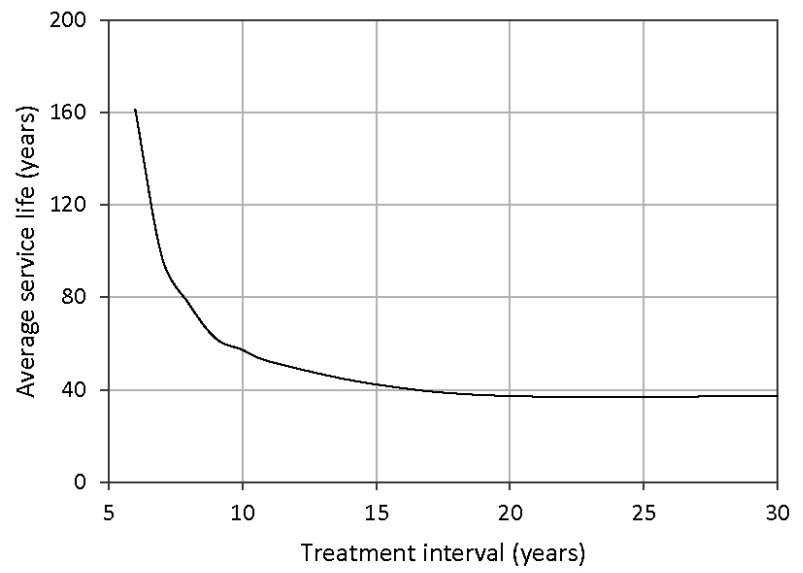




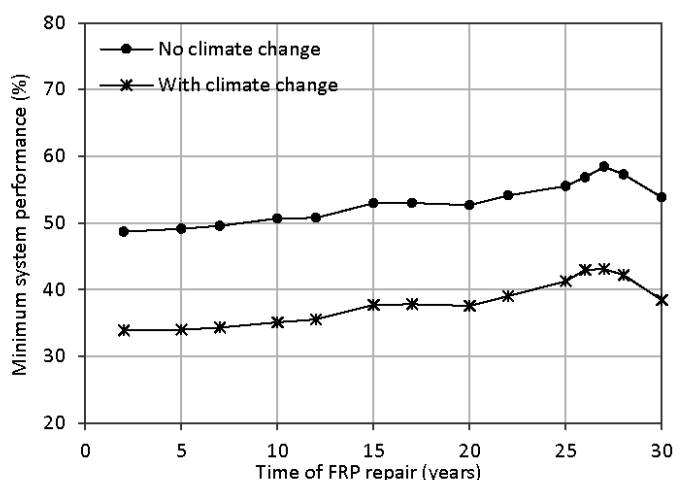

(a)

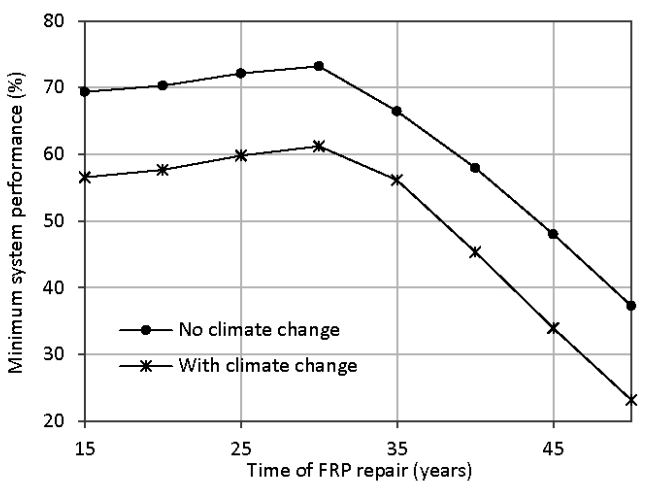

(b) 


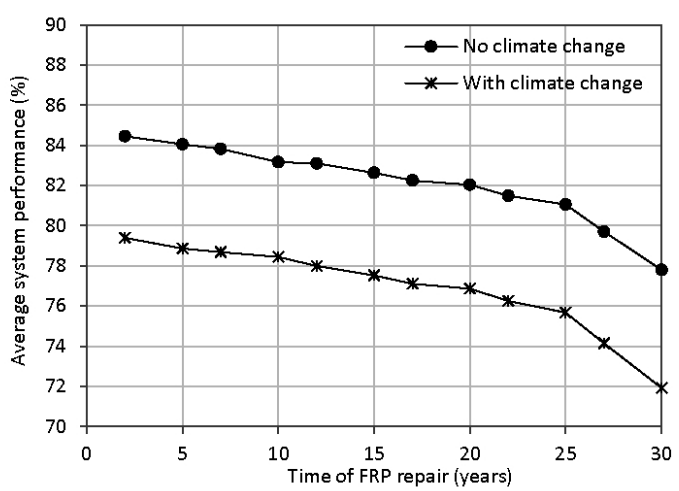

(a)

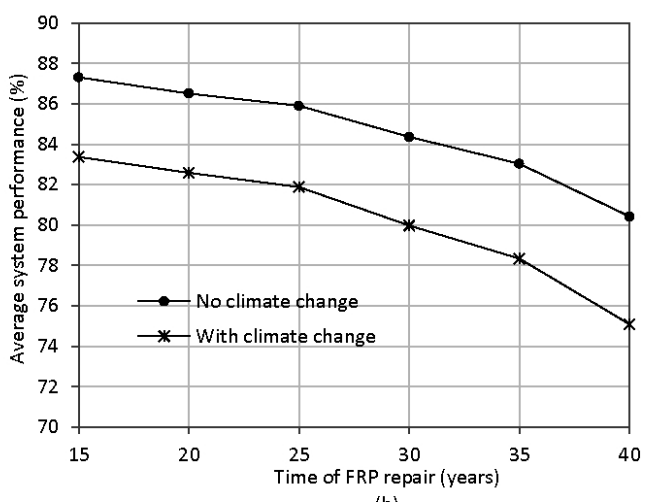

(b) 

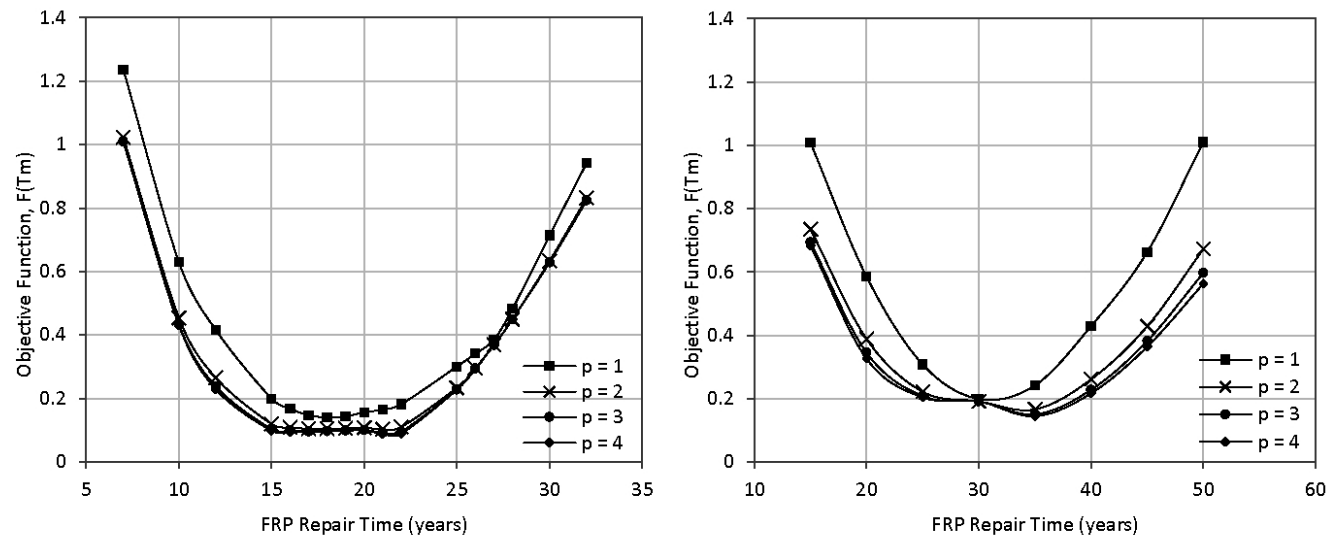


\section{Maintenance Optimization for Power Distribution Systems Subjected to Hurricane Hazard, Timber Decay and Climate Change}

\section{Highlights:}

$>$ A framework for optimal maintenance of wood poles under hurricane hazard, climate change, and decay is proposed.

$>$ The service life of poles, maintenance cost, and system performance were considered.

$>$ Time-based chemical treatment of wood poles and repair using fiber reinforced polymer were considered.

The impact of climate change can be significant and should be considered in a long-term asset management plan.

$>$ Delaying preventive maintenance of poles can increase service life but also increase component risk. 